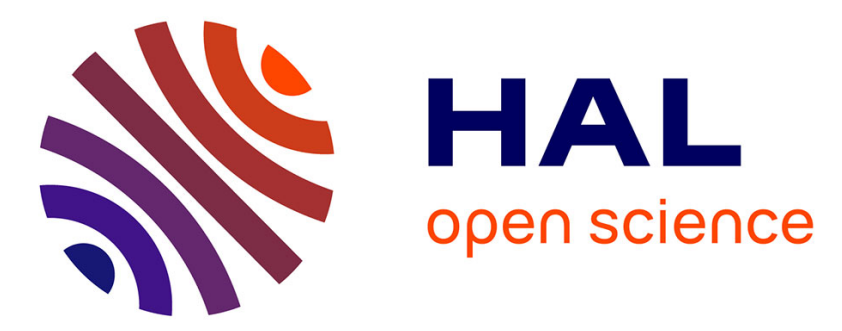

\title{
Gas-solid interface charge tailoring techniques: what we grasped and where to go
}

Zhousheng Zhang, Zheming Wang, G. Teyssedre, Tohid Shahsavarian, Mohamadreza Arab Baferani, Geng Chen, Chuanjie Lin, Bo Zhang, Uwe Riechert, Zhipeng Lei, et al.

\section{To cite this version:}

Zhousheng Zhang, Zheming Wang, G. Teyssedre, Tohid Shahsavarian, Mohamadreza Arab Baferani, et al. Gas-solid interface charge tailoring techniques: what we grasped and where to go. Nanotechnology, 2021, 32 (12), pp.122001. 10.1088/1361-6528/abccea . hal-03326097

\section{HAL Id: hal-03326097 https://hal.science/hal-03326097}

Submitted on 25 Aug 2021

HAL is a multi-disciplinary open access archive for the deposit and dissemination of scientific research documents, whether they are published or not. The documents may come from teaching and research institutions in France or abroad, or from public or private research centers.
L'archive ouverte pluridisciplinaire HAL, est destinée au dépôt et à la diffusion de documents scientifiques de niveau recherche, publiés ou non, émanant des établissements d'enseignement et de recherche français ou étrangers, des laboratoires publics ou privés. 


\title{
Gas-solid Interface Charge Tailoring Techniques: What We Grasped and Where to Go
}

\author{
Zhousheng Zhang', Zheming Wang ${ }^{1}$, Gilbert Teyssedre'2, Tohid Shahsavarian ${ }^{3}$, \\ Mohamadreza Arab Baferani ${ }^{3}$, Geng Chen ${ }^{4}$, Chuanjie Lin ${ }^{5}$, Bo Zhang ${ }^{6}$, Uwe \\ Riechert ${ }^{7}$, Zhipeng $\mathrm{Le}^{8}$, Yang $\mathrm{Cao}^{3 *}$, Chuanyang $\mathrm{Li}^{3 *}$
}

\author{
${ }^{1}$ School of Electrical Engineering, Shanghai University of Electric Power, Changyang Road \#2588, Shanghai, 200090, \\ People's Republic of China \\ ${ }^{2}$ Laplace, Paul Sabatier University, and CNRS, Toulouse, France \\ ${ }^{3}$ Electrical Insulation Research Center, Institute of Materials Science, Electrical and Computer Engineering, University of \\ Connecticut, Storrs, CT 06269, USA \\ ${ }^{4}$ Beijing Area Major Laboratory of High Voltage and Electromagnetic Compatibility, North China Electric Power University, \\ Beijing 102206, People's Republic of China
}

${ }^{5}$ State Key Laboratory of Power Systems, Department of Electrical Engineering, Tsinghua University, Beijing, 100084, People's Republic of China

${ }^{6}$ State Key Laboratory of Electrical Insulation and Power Equipment, Xi'an Jiaotong University,Xi'an 710049, China

${ }^{7}$ ABB Switzerland Ltd, High Voltage Products, Zurich, Switzerland

${ }^{8}$ Shanxi Key Laboratory of Mining Electrical Equipment and Intelligent Control, College of Electrical and Power Engineering, Taiyuan University of Technology, Taiyuan 030024, China

*Corresponding authors: yang.cao@uconn.edu; lichuanyangsuper@163.com

\begin{abstract}
Charging of insulators modifies local electric field distribution and increases potential threat to the safety of the gas insulated equipment. In this paper, surface charge tailoring techniques are classified and reviewed by introducing a Dam-flood model. Technical solutions of different charge tailoring methods are compared and discussed. The outlook of potential solutions to suppress charge accumulation is recommended and discussed based on industrial consideration. This paper serves as a guide handbook for engineers and researchers into the study of charge tailoring methods. Meanwhile, we hope that the content of this paper could shed some lights upon charge-free insulators to promote the industrial application of HVDC GIL/GIS.
\end{abstract}

Keywords: Epoxy resins; direct fluorination; surface charge migration; DC surface flashover; HVDC GIL.

\section{Introduction}

Surface charge accumulation at the surface of insulators inside the HVDC GIL results in electric field distortion and potentially triggers the surface flashover [1]. The pioneering research dates back to 1982 when Cooke found that the insulator surface accumulates charges when the surface charge arrival rate exceeds the surface charge conduction rate [2]. Since then, studies regarding gas-solid interface charge behaviors and 
characterization techniques [3] as well as charge tailoring methods begin to draw worldwide attentions. Efforts have been paid to control these charges, in which the implementation of nano coatings and fillers played very important role in dielectric property enhancement [4-10].

Nanodielectrics attract more attentions in recent years. The DC conductivity of polyaniline was found increased by doping with $\mathrm{TiO}_{2}$ nano-fillers, and a very large dielectric constant of about 3700 at room temperature was observed [4]. According to literature 5, a consistency between predictions and impedance measurements verifies the impact of atomic coordination-number imperfection on the dielectric performance of nanometric semiconductors. The effectiveness of nano-fillers is also verified in literature 7 and 8 that a decrease in surface charge accumulation and an increase in surface flashover voltage were obtained. Results from literature 9 again verified that an ordered and nonlinear nano coating introduced on epoxy surface serves as a useful way to decay surface charges and increase surface flashover voltage. A surface treatment creating a nano surface layer by DBD plasma also decays surface charge effectively when using silicone rubber as a base material [10].

In recent years, due to the urgent requirement of HVDC GIL driven by the expansion of HVDC projects, especially offshore projects, the problem of surface charge accumulation has become tremendously pronounced [11-14]. As a consequence, extensive research studies regarding surface charge behavior has become a focus which is a specific challenge [7-10]. However, suitable surface charge tailoring methods still remain to be a difficult problem which captures the interests of researchers.

It has been accepted that the surface charge is either from the conducting current from the volume/surface, or due to charge transport along the direction of electric field lines in the gas phase [15]. Meanwhile, it has been indicated that due to the differences in local electric field stress, dominant charge types at different positions of the insulator are field-dependent, as shown in Figure 1 [16]. Surface flashover at DC voltage has been verified to be triggered by expansion of analogous ineffective region due to homo-polar charge injection [17]. Recent study verifies that the evolution of surface charge clusters, presented by dust phase transition, plays a key role in triggering unpredictable insulation surface flashover [14]. Accordingly, when dealing with methods to suppress the surface charge accumulation, it is very important to firstly clarify the dominant charge origin and charge property, as well as the way these charges influence surface flashover voltage under 
specific insulation-electrode arrangement. Bearing in mind this we can further consider suitable manners targeting the decay of these charges.

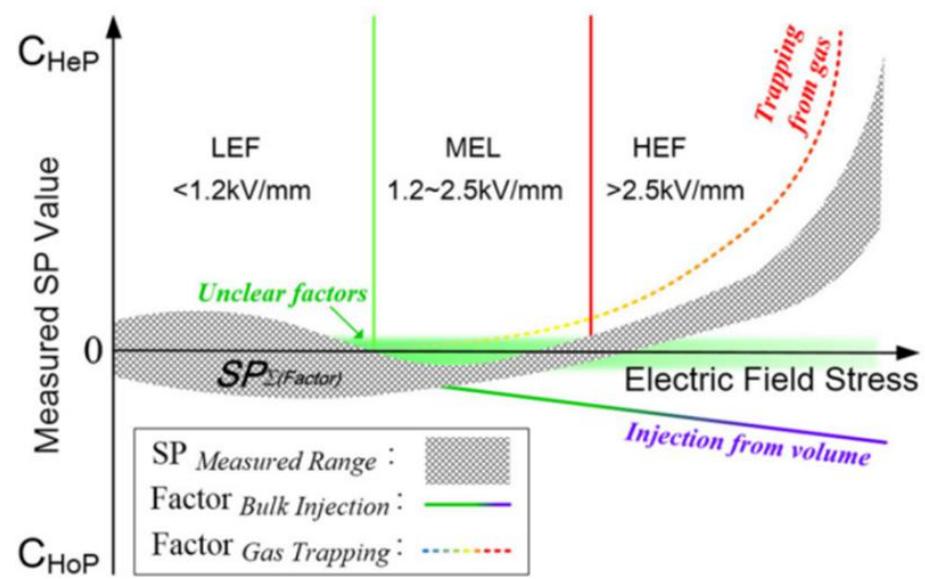

Figure 1. Field-dependent model of dominant charge behavior. Unclear factors represents electrostatic charges, bulk charges, charges from cosmic or PDs, and polarization in the volume, etc.; trapping from gas represents enhanced gas ionization following Townsend's law; injection from volume represents charges injected from volume; $\mathrm{SP}, \mathrm{C}_{\mathrm{He}} \mathrm{P}$, and $\mathrm{C}_{\mathrm{Ho}} \mathrm{P}$ stand for surface potential, hetero-polar charge and homo-polar charge [16].

In this paper, to help the reader identify the source of the charge at the gas-solid interface, which is very important while usually be neglected, and the suppression methods more intuitively, we introduce a Dam model to explain interestingly how gas-solid interface charges are categorized based on which the corresponding charge tailoring methods are reviewed and discussed. The outlook of potential solutions to suppress charge accumulation is recommended and discussed based on industrial consideration. We hope that this paper can be useful for engineers and researchers into the study of charge modification methods and could shed some lights upon charge-free insulators to promote the industrial application of HVDC GIL/GIS.

\section{Dam-flood model}




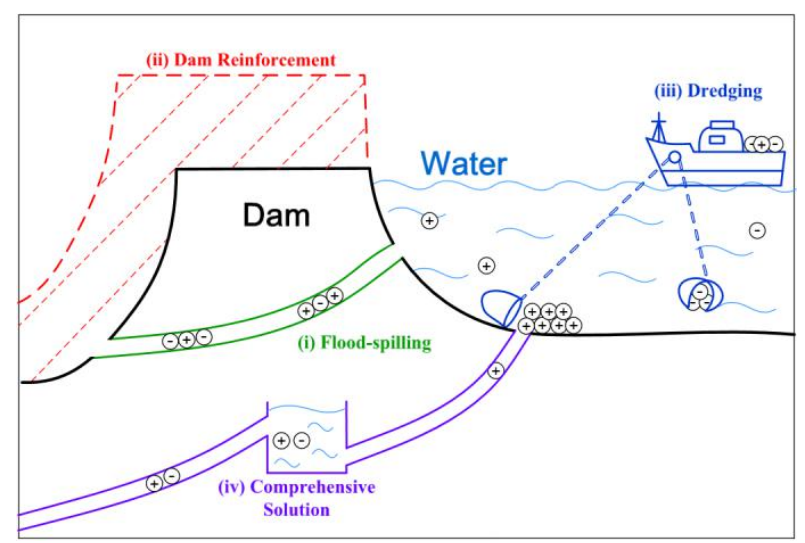

Figure 2. Equivalent diagram of Dam-flood model.

Table1. Flood-dam model and the corresponding surface charge tailoring techniques.

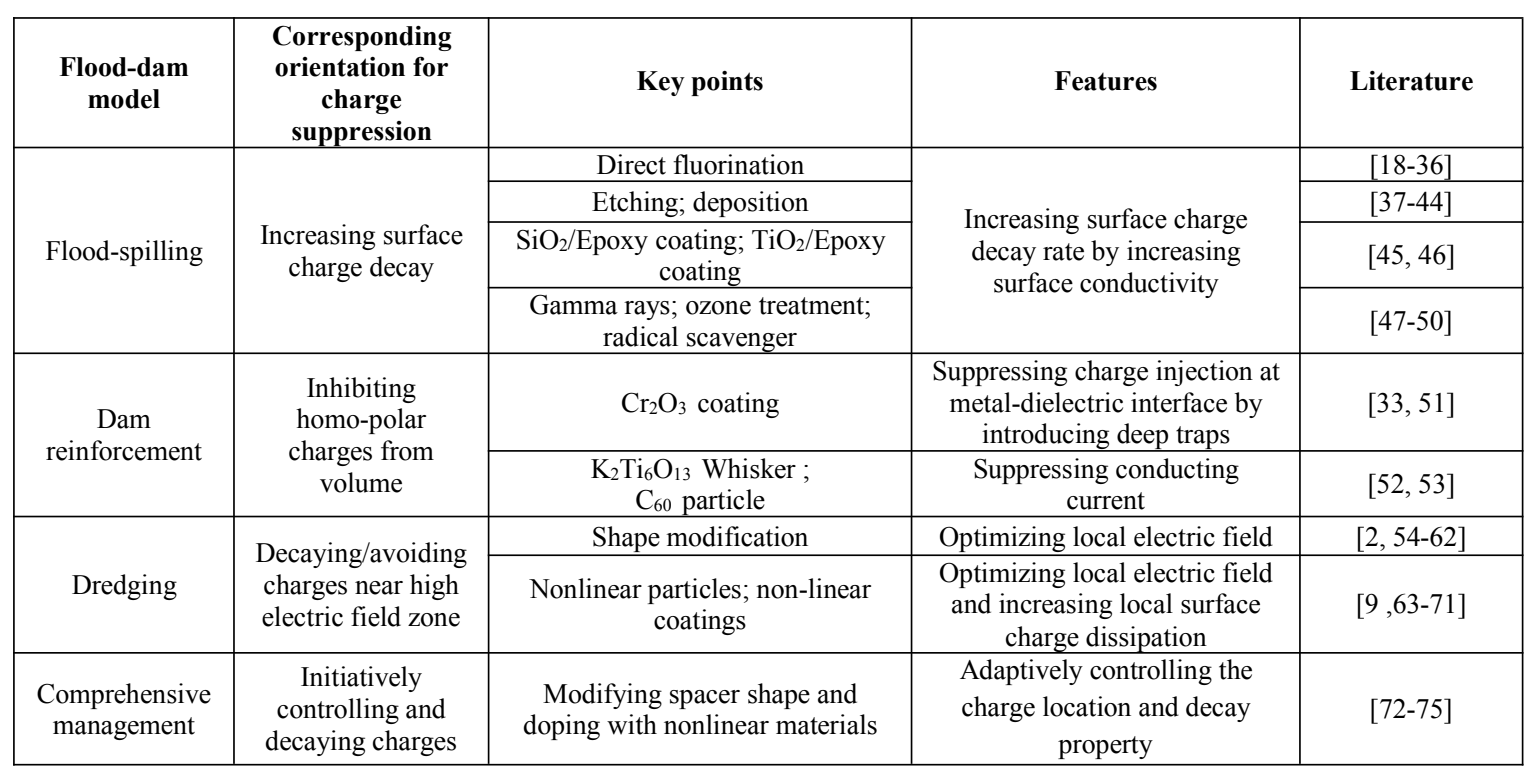

Causing heavy casualties, the flood to houses and populations is equivalent to the charge triggered surface flashover to gas insulated electric power systems. The triggering process for floods can be slow which is due to the destruction/degradation of the forest over years, while some types of floods can be developed over a few days due to continuous heavy rain drop. Correspondingly, surface charge accumulation on the insulator can be a very slow process due to numerous discrete processes on smallest scale, e.g. charge injection/extraction at the electrode-insulation interfaces, trapping and de-trapping, charge generation and recombination, polarization, etc. [76], while in some cases the surface charge amount can be increased dramatically in a short period in case of ionization due to local metal particles [2].

The dam, representing as the insulator to separate high voltage from the ground, is a barrier that restricts or stops the flow of water and suppresses progression of the floods. The solution for flood control via the 
construction of a dam can be divided into four aspects: Flood spilling, dam strengthening, dredging and comprehensive management, which corresponds to different charge tailoring orientations, as shown in Table 1 and Figure 2. To be more specific, in case when the upstream water level rises, spilling prevents flooding in a manner of keeping water flowing downstream, which is equivalent to increase the surface charge decay rate to have a lower amount of surface charges; By dam reinforcement, the dam becomes stronger so that the water pressure does not endanger the safety of the dam, which is equivalent to increasing the inception electric field for charge injection so as to suppress injected homo-polar charges; Dredging is a commonly used approach to increase the canal depth and therefore increase the capacity of canals for carrying water/floods. Regarding the charge tailoring solution, by means of material modification and shape improvement, local electric field can be optimized and the withstand voltage of the spacer can thereby be increased; Based on canal diversion, the sediments can be dredged and saved for farmlands and the flood can be prevented. Such comprehensive management methods have the synergistic effect to control surface charges of insulators, i.e. to control the position of charges and initiatively decay these charges. The Dam model constituents and the corresponding surface charge tailoring techniques can also be found in Table 1.

\section{Flood-spilling-increasing surface charge decay}

Given the idea of Flood spilling, a more conductive surface with higher surface decay rate is obtained. Capability of fluorination, plasma treatment, surface coatings, gamma ray irradiation, and ozone treatment, etc., have been verified in increasing the surface conductivity and surface charge decay by researchers [30, 33, $37,45,47,49]$. This chapter firstly reviews the results from the above mentioned methods, and a comparative analysis among the research characteristics from each research group is presented.

\subsection{Surface fluorination}

Surface fluorination treatment is performed based on the interaction between fluorine gas and the polymer surface. A stable C-F surface layer with different byproducts can be formed and thereby the surface property can be controlled [24] and a fluorinated coating with certain surface conductivity is obtained.

\subsubsection{Researches in Tongji University}


In 2011, Z. An et al. conducted pioneering researches on surface fluorination treatments on epoxy resin [20]. They used an $\mathrm{F}_{2} / \mathrm{N}_{2}$ mixture with a volume of $12.5 \% \mathrm{~F}_{2}$ to fluorinate the epoxy resin sheet with a thickness of $0.55 \mathrm{~mm}$, and the results showed that the surface conductivity was increased from $1.1 \times 10^{-17} \mathrm{~S}$ to $8.7 \times 10^{-14} \mathrm{~S}$, with a value increasing by 3 orders of magnitude. They believed that the decrease of surface trap depth and the adsorption of water on the surface in the vicinity of air are the main reasons responsible for increase of surface conductivity. Based on their preliminary results, they modified epoxy sheet to suppress the accumulation of surface charges effectively by introducing a surface with lower conductivity through the fluorination[19]. In order to further understand the mechanism of the suppression of the charge accumulation on the insulator surface, they further studied the effect of temperature and fluorination duration on electrical properties of epoxy based materials [21].

Figure 3 shows the surface conductivities of the epoxy before and after fluorination. The results showed that the surface conductivity of the fluorinated sample at various humidity levels is significantly higher than the untreated sample, and the surface conductivity increases with the increase of the fluorination temperature. They concluded that the increase in fluorination temperature increases surface conductivity (from $10^{-17} \mathrm{~S}$ to $10^{-13} \mathrm{~S}$ at $20 \%$ relative humidity level ).

Further, they showed that the surface conductivity of samples can be related to fluorination time duration at different relative humidity levels [22]. Figure 4 shows the surface conductivity of the original and surface

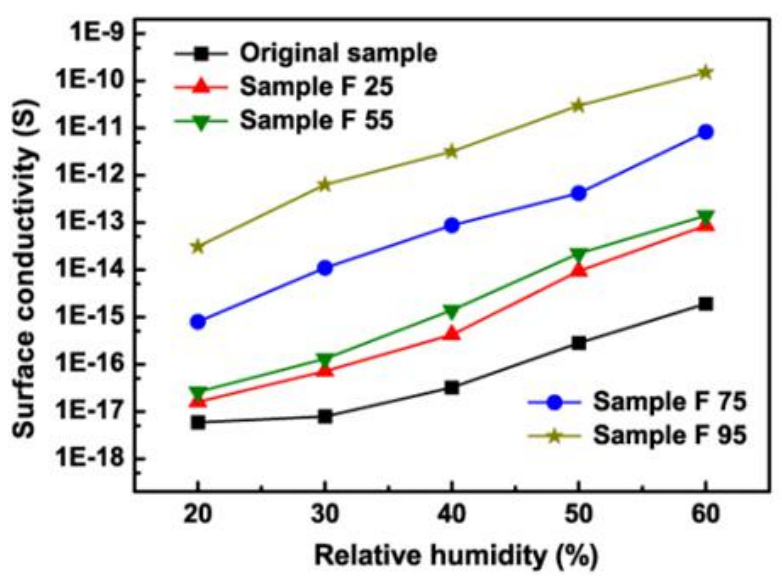

Figure 3. Surface conductivity measured at different RH levels and room temperature for the original sample and samples fluorinated at $25,55,75$, and $95^{\circ} \mathrm{C}[21]$. 


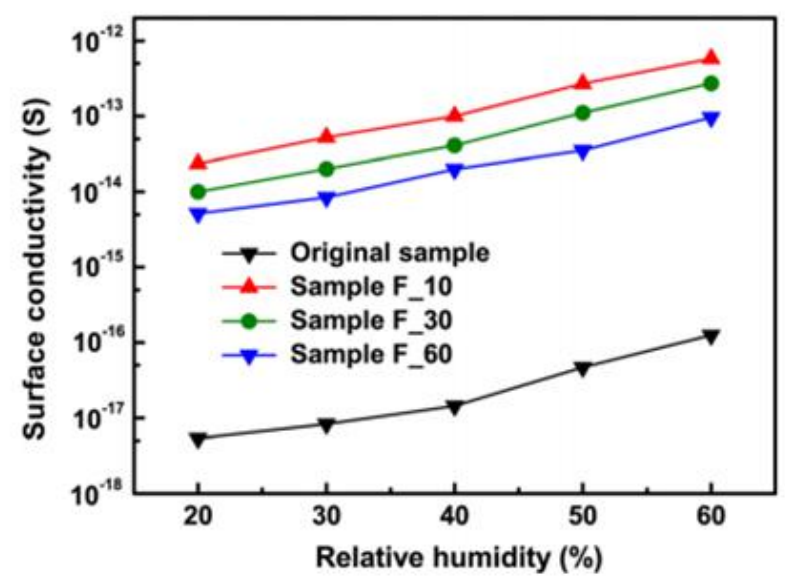

Figure 4. Surface conductivity at different RH levels for the untreated and surface fluorinated samples for times of 10, 20 and $30 \mathrm{~min}[22]$.

fluorinated samples at different relative humidity levels. The results show that as the fluorination time duration increases, the surface conductivity increases, while this trend is opposite in case of humidity changes.

They concluded that temperature and fluorination time duration are two important factors controlling the fluorination process and the surface conductivity, noting that the effect of temperature on the surface conductivity is more significant than that of the fluorination time duration [18]. In subsequent researches, they investigated the discharge characteristics and $\mathrm{AC} / \mathrm{DC}$ flashover performance of surface fluorinated epoxy insulators $[23,36]$.

\subsubsection{Researches in University of Southampton}

G. Chen et al. employed the same fluorination treatment method on the epoxy films [27-29]. Compared with Z. An's work, G. Chen's research paid more attention on the breakdown property of the epoxy. They found that with the prolongation of the fluorination time duration, the surface flashover voltage was increased significantly. Meanwhile, their results showed that the leakage current increases with the fluorination duration, which is different compared with results obtained by other researchers [19-21, 32]. As shown in Figure 5, the leakage current of samples fluorinated for $30 \mathrm{mins}$ and $60 \mathrm{mins}$ are $2.4 \times 10^{-11} \mathrm{~A}$ and $4.12 \times 10^{-11} \mathrm{~A}$, respectively, which is much higher than that of the untreated sample. 


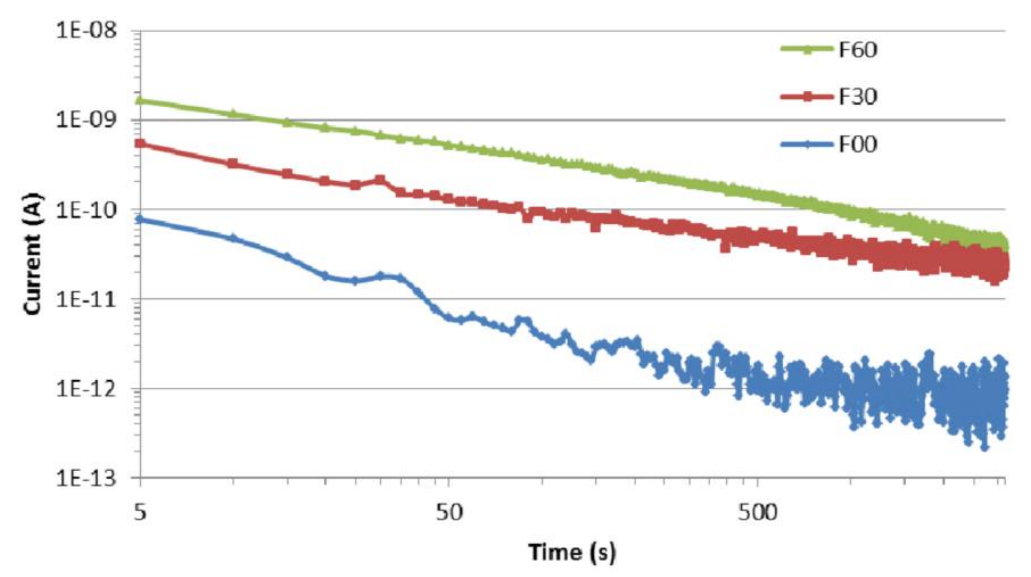

Figure 5. DC conductivity measurement for $250 \mu \mathrm{m}$ epoxy resin sample being treated after different fluorination time [29].

In their subsequent studies, they paid more attention to the charge suppressing mechanism [25]. They believed that the increase in the surface conductivity may not be due to the fluorine layer itself, but because of the moisture absorbed by the surface layer [26]. It is interesting to note that according to a recent report, the conductivity of the fluorinated layer has a negative correlation with increase of the temperature [15], while the result provided by G.Chen implies that increase of the conductivity by fluorination process is due to absorbed surface moisture, which can be the rationale behind this phenomenon.

\subsubsection{Researches in Tianjin University}

B. Du et al. Studied the surface charge decay property of fluorinated epoxy samples [30]. The surface flashover voltage of samples with different fluorination time durations are evaluated. They introduced the carrier mobility and trap distributions to analyze the effect of fluorination on surface charge behaviors and flashover characteristics [30]. Furthermore, a novel cone-type insulator with surface conductivity gradient based on direct fluorination treatment was developed, as shown in Figure 6 [31].The results showed that the flashover voltage of the $\sigma-\mathrm{FGM}$ insulator is $36.3 \%$ higher than that of the traditional insulator due to a uniform electric field distribution. 


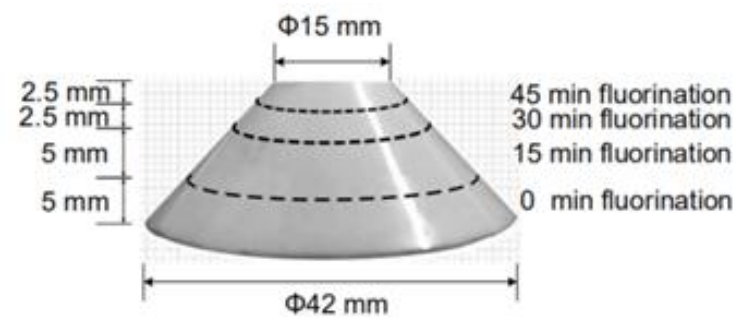

Figure 6. Insulators with interfacial $\sigma$-FGM: a four-gradient tapered insulator (F-45-30-15-0) [31].

\subsubsection{Researches in Tsinghua University}

Following Z. An 's pioneering research regarding fluorination of epoxy resin, J. He et al. focused mainly on surface fluorination treatment of $\mathrm{Al}_{2} \mathrm{O}_{3}$ filled epoxy resin insulators, which pushed these researches much closer to the industry applications [24]. In their studies, different surface modification methods are employed to evaluate the effect of fluorination on epoxy based insulation products $[32,33,35]$,

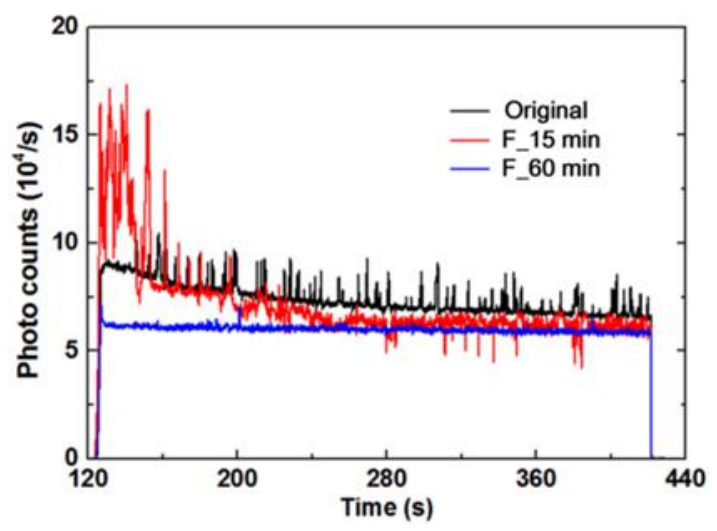

Figure 7. Electroluminescence intensity of samples before and after surface fluorination at -20kV [34].

Electroluminescence as a parameter to characterize epoxy-based composites before and after fluorination was introduced [34]. Here electroluminescence is defined as a surface light emission that may involve both solid and gas emissions following impact by energetic carriers. It has to be distinguished from pure bulk emission from solids that normally require higher fields to be triggered $[77,78]$. The results showed that the electroluminescence curve of the sample after fluorination is more stable than that of the non-fluorinated sample (as shown in Figure 7), and the EL pulse corresponding to the F_60 min sample is significantly suppressed. They believed that the surface of the sample becomes flatter after fluorination, thereby the micro plasma activities due to the concentration of the electric field on the surface alumina edges and corners at the 
gas-solid-conductor triple junction are suppressed. They emphasized that these micro-discharges are likely to be a potential consequence of surface heteropolar charges and can thereby increase the possibility of undetermined surface flashover under both AC and DC voltage, which were also discussed in their follow-up research work $[14,79]$. In 2017, the physical mechanism of fluorination on carrier migration and the impact on flashover voltage were explored and the inhibitory effect of fluorination on surface discharge corrosion was preliminary studied( as shown in Figure 8(a)) [35]. Z. An further studied the improvement of surface electro-corrosion performance by fluorination in 2019 [23]( as shown in Figure 8(b)). Both researches confirmed the resistivity of the fluorinated epoxy surface layer to corona discharge is significantly improved $[23,35]$.
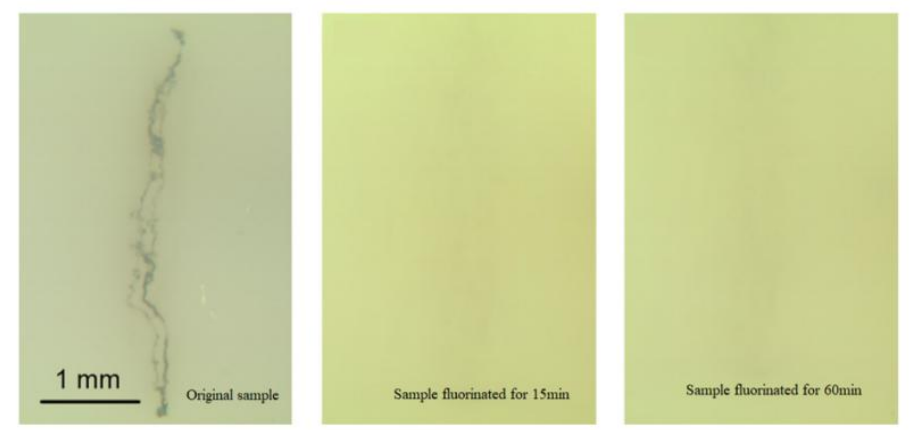

(a)

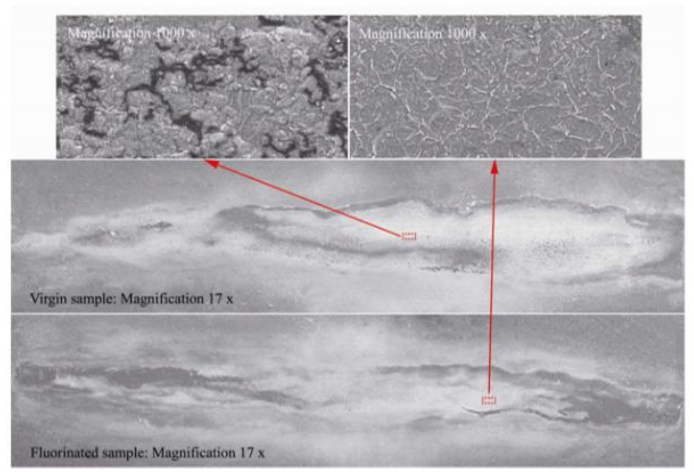

(b)

Figure 8. (a) Surface image of experimental samples before and surface flashover in $\mathrm{SF}_{6}$ [35];(b) SEM photographs of the discharge degraded surface of the virgin and the fluorinated samples respectively after the 5 th and 10th flashover [23].

\subsubsection{Analysis and discussion}

Looking at the similarities of the results in these 4 different groups, we can conclude that several key parameters play important roles in determining surface properties, among which the surface conductivity, trap distribution, surface morphology significantly affect the surface charge decay and surface flashover voltage. 
Table 2. Fluorination test conditions and results of different research groups.

\begin{tabular}{|c|c|c|c|c|c|c|c|c|}
\hline \multirow[b]{2}{*}{ Authors } & \multirow[b]{2}{*}{ Ref. } & \multirow[b]{2}{*}{ Matrix } & \multicolumn{3}{|c|}{ Surface conductivity test conditions } & \multicolumn{2}{|c|}{ Fluorination parameter } & \multirow[b]{2}{*}{$\begin{array}{c}\begin{array}{c}\text { Surface } \\
\text { conductivity } \\
\left(1^{-18} \mathbf{S}\right)\end{array}\end{array}$} \\
\hline & & & $\begin{array}{c}\text { Ambient } \\
\text { gas }\end{array}$ & $\begin{array}{c}\text { Temperature } \\
\left({ }^{\circ} \mathrm{C}\right)\end{array}$ & $\begin{array}{l}\text { Relative } \\
\text { humidity }\end{array}$ & $\begin{array}{c}\text { Fluorination } \\
\text { temperature } \\
\left({ }^{\circ} \mathrm{C}\right)\end{array}$ & $\begin{array}{c}\text { Fluorination } \\
\text { time (mins) }\end{array}$ & \\
\hline \multirow{14}{*}{ Z. An } & \multirow{5}{*}{ [21] } & \multirow{5}{*}{$\begin{array}{l}\text { Epoxy } \\
\text { resin }\end{array}$} & \multirow{5}{*}{ Air } & \multirow{5}{*}{25} & \multirow{5}{*}{$20 \%$} & - & - & 7 \\
\hline & & & & & & 25 & \multirow{4}{*}{30} & 20 \\
\hline & & & & & & 55 & & 40 \\
\hline & & & & & & 75 & & 900 \\
\hline & & & & & & 95 & & 50000 \\
\hline & \multirow{5}{*}[18]{} & \multirow{5}{*}{$\begin{array}{l}\text { Epoxy } \\
\text { resin }\end{array}$} & \multirow{5}{*}{$\begin{array}{c}\text { High } \\
\text { purity } \mathrm{N}_{2}\end{array}$} & \multirow{5}{*}{25} & \multirow{5}{*}{$20 \%$} & - & - & 9 \\
\hline & & & & & & 25 & \multirow{4}{*}{30} & 10 \\
\hline & & & & & & 55 & & 30000 \\
\hline & & & & & & 75 & & 300000 \\
\hline & & & & & & 95 & & 800000 \\
\hline & \multirow{4}{*}{ [22] } & \multirow{4}{*}{$\begin{array}{l}\text { Epoxy } \\
\text { resin }\end{array}$} & \multirow{4}{*}{ Air } & \multirow{4}{*}{25} & \multirow{4}{*}{$20 \%$} & - & - & 7 \\
\hline & & & & & & & 10 & 40000 \\
\hline & & & & & & 50 & 30 & 10000 \\
\hline & & & & & & & 60 & 8000 \\
\hline & & & & & Before & - & - & 1886 \\
\hline & & & & & drying & 50 & 60 & 4940 \\
\hline & [26] & Epoxy & Air & 25 & $\begin{array}{l}\text { After } \\
\text { vacuum }\end{array}$ & - & - & 1406 \\
\hline & [20] & resin & & & drying & 50 & 60 & 2040 \\
\hline G. Chen & & & $\mathrm{N}_{2}$ & 25 & After $\mathrm{N}_{2}$ & - & - & 1406 \\
\hline & & & $1 v_{2}$ & $2 J$ & drying & 50 & 60 & 3480 \\
\hline & & & & & & - & - & 113.2 \\
\hline & [25] & 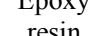 & Air & 25 & mentioned & 50 & 30 & 432 \\
\hline & & & & & & 50 & 60 & 1006 \\
\hline & & & & & & - & - & 450 \\
\hline & & & & & & & 15 & 800 \\
\hline B. Du & [31] & Epoxy & Air & 25 & Under $30 \%$ & 25 & 30 & 1400 \\
\hline & & & & & & 25 & 45 & 1790 \\
\hline & & & & & & & 60 & 1900 \\
\hline & & & & & & - & - & 0.00097 \\
\hline & [24] & Epoxy & $\begin{array}{c}\text { Hign } \\
\text { purity } \mathrm{N}_{2}\end{array}$ & 25 & Under $10 \%$ & & 15 & 370 \\
\hline & & $/ \mathrm{Al}_{2} \mathrm{O}_{3}$ & & & & 50 & 30 & 21 \\
\hline & & & & & & & 60 & 0.86 \\
\hline & & & & & & - & - & 0.88 \\
\hline J. He & {$[32]$} & Epoxy & Air & 16 & $10 \%-14 \%$ & & 15 & 368 \\
\hline & & $\mathrm{Al}_{2} \mathrm{O}_{3}$ & & & & 50 & 30 & 20.5 \\
\hline & & & & & & - & 00 & 0.86 \\
\hline & & & $\mathrm{SF}_{6}$ & & & & 15 & $\frac{0.892}{374}$ \\
\hline & [32] & $/ \mathrm{Al}_{2} \mathrm{O}_{3}$ & & 16 & $10 \%-14 \%$ & 50 & 30 & 21 \\
\hline & & & & & & & 60 & 0.864 \\
\hline
\end{tabular}

However, based on the results of previously published literature, it is still difficult to confirm which parameter plays dominant role on surface charge decay process and surface flashover property. Table 2 shows the surface conductivity values presented in different research studies. Two general conclusions can be obtained: (1) The surface conductivity is increased dramatically with short fluorination time (within 30mins), while it decreased when the samples are treated after long term fluorination, except for results obtained by G.Chen [27, 28]. (2) The decreasing rate of conductivity with fluorination time duration accelerates with increase of temperatures. Apart from that, based on the results presented in [21][22][24] and [32], the surface conductivity of untreated epoxy or epoxy based composites ranges from $9 \times 10^{-22} \mathrm{~S}$ to $7 \times 10^{-18} \mathrm{~S}$, with the difference up to 1 to 
4 orders of magnitude in their values. Usually, the leakage current has very large difference with respect to electric field, temperature and duration of applied dc voltage. Meanwhile, if the measurement was repeated for several times, the injected charges and depolarization process from previous tests can further influence the leakage current, resulting in a lower leakage current value. When it comes to samples after fluorination, we can find some similarity that the surface conductivity can be increased by 3-5 orders of magnitude with short fluorination time, while the long fluorination time results in a surface with conductivity similar to the untreated samples. This finding is applicable to both alumina-doped epoxy and pure epoxy.

It has been widely accepted that a higher surface conductivity results in a higher surface charge decay rate. However, it should be pointed out that the increase in surface flashover voltage due to fluorination cannot merely be attributed to increase of charge decay kinetics. In [32], the surface conductivity of fluorinated sample for $60 \mathrm{~min}$ is $8.64 \times 10^{-19} \mathrm{~S}$, which is slightly lower than the surface conductivity of untreated samples $8.92 \times 10^{-19} \mathrm{~S}$ (refer to Table 2), while the flashover voltage, similar to that with short fluorination time, is much higher than the untreated sample (as shown in Figure 9). We believe that the surface morphology after long fluorination time has more influence on surface flashover voltage than the surface charge decay.

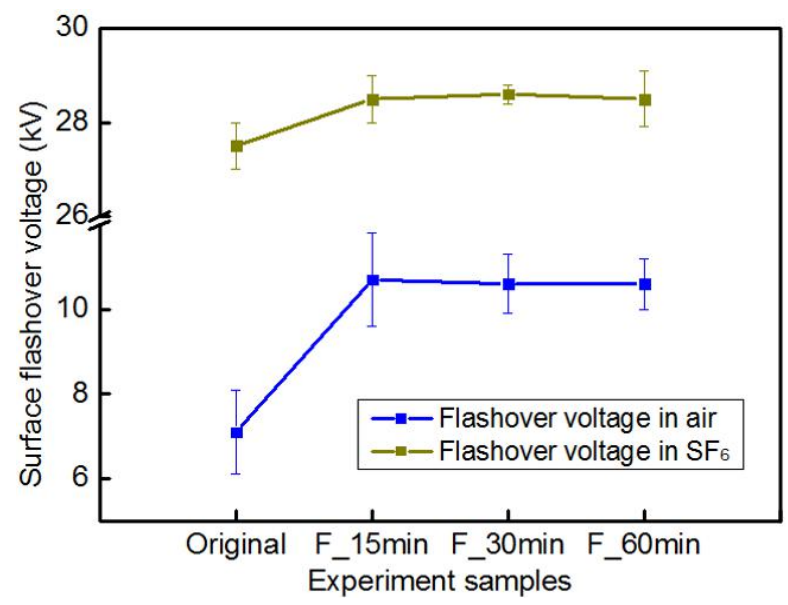

Figure 9. The DC surface flashover voltage of original and fluorinated samples for $15 \mathrm{~min}, 30 \mathrm{~min}$ and 60 min in air and $\mathrm{SF}_{6}[32]$.

Considering the feasibility of industrial applications, fluorination is applicable to insulators of any shape and size. However, it has disadvantages such as: the mechanism of the fluorination is complex, which needs further investigation. In addition, it is still unclear that the fluorinated coating can be stable since insulators are exposed to temperature variation under dc voltage. As for the aging of the fluorination layer, T. Shao tested 
the surface charge decay rate using sheet samples, and the results showed that there is no obvious aging effect after 5 days storage of the directly fluorinated samples in ambient air [41]. However, the experiment was conducted in the ambient air, which cannot demonstrate real operation condition subjected to temperature and electric field changes, so it cannot be regarded as a direct fluorination stability test.

As reported in our recently published paper, the conductivity of the fluorinated layer has a negative correlation with the increase of temperature (as shown in Figure 10). This means that when the temperature rises, the conductivity of the fluorinated layer decreases, which can reduce the rate of charge dissipation [15]. This process has been verified, which is not reversible. In this case, the surface charge decay rate for short time fluorianted spacer would somehow be affected.

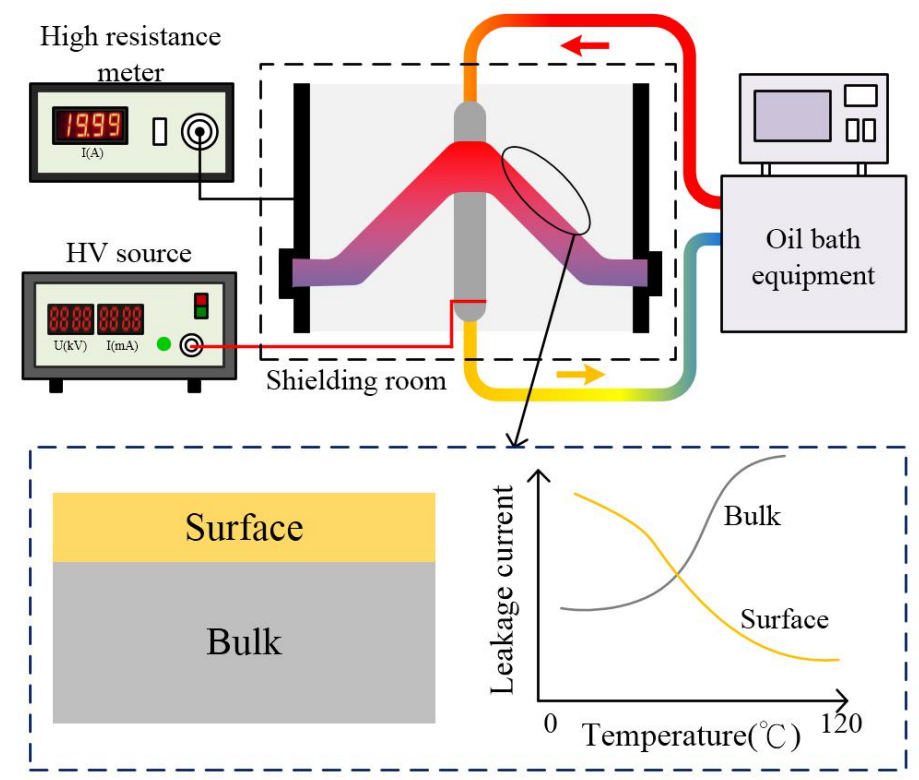

Figure 10. Stable surface leakage current and bulk leakage current changing trend with the increase of temperature using a new short time fluorinated spacer [15].

\subsection{Plasma treatment}

Plasma refers to an ionized gaseous medium which consists of a gas of ions and free electrons. Based on its unique property, it can be used to modify dielectric surface, modifying surface trap level distribution, carrier mobility, and surface conductivity of the material [37, 38, 40, 41]. Commonly used low-temperature plasma-treated discharge includes dielectric barrier discharge (DBD), atmospheric pressure plasma jet (APPJ), and the like. In this section, we focus on studies regarding plasma-treated surface and the dielectric property enhancement. 


\subsubsection{Researches in Chinese Academy of Sciences}

Electrons in non-thermal plasmas can induce molecule excitation, ionization and dissociation, hence, resulting in the chemical bonds breaking for surface modification [80, 81]. T. Shao et al. performed pioneering studies over DBD plasma treatment in epoxy based polymers and found that the plasma treatment effectively increases the surface hydrophilicity of epoxy resin, which in turn augments surface charge decay rate [38]. Meanwhile, the anti-aging property of the epoxy-based samples was studied. Figure 11 shows the surface potential decay of samples after the plasma treatment. Samples were charged by corona discharges with a
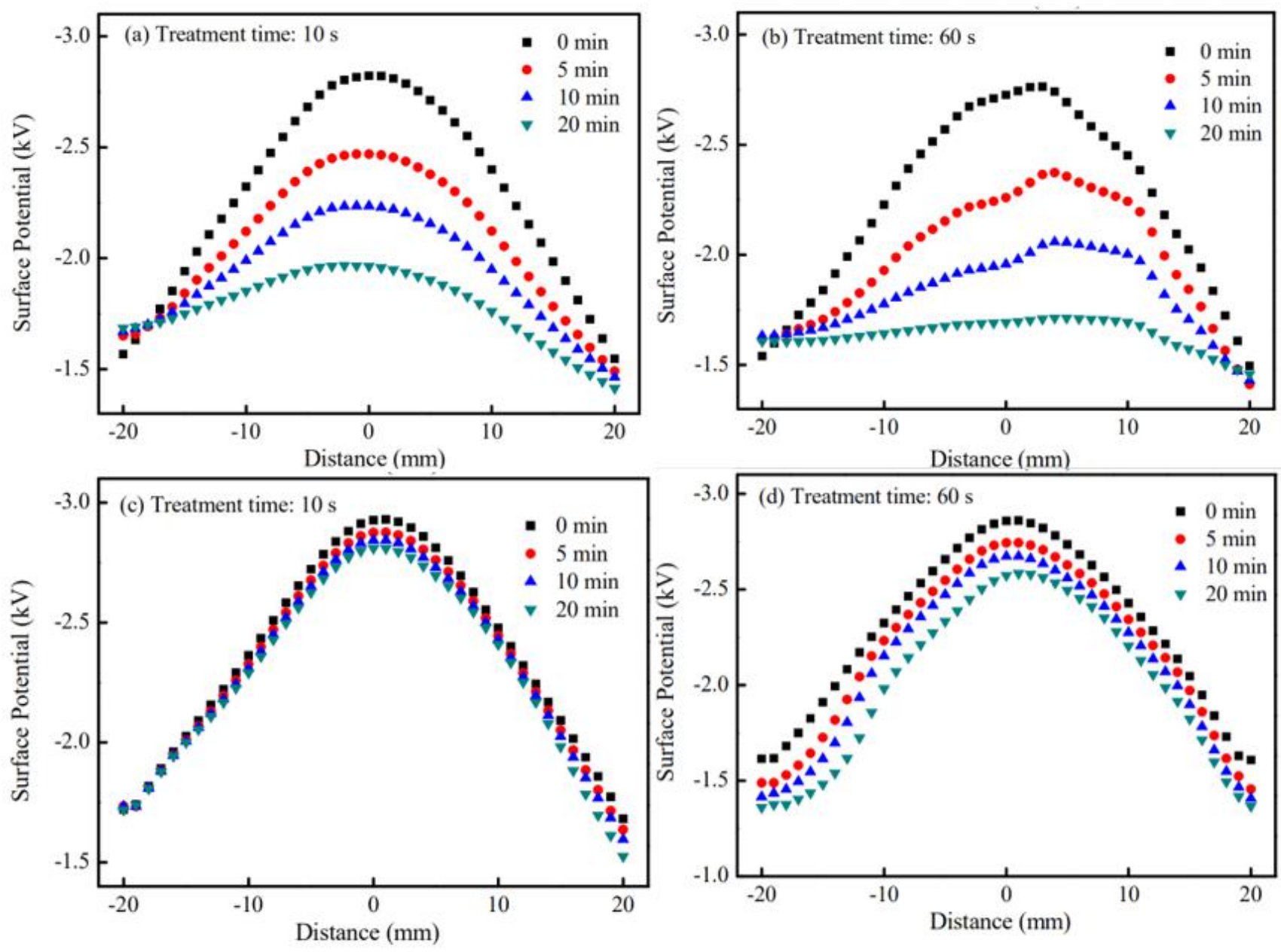

Figure 11. The surface potential decay of epoxy samples aging effect (a) and (b) with plasma treatment time 10 and $60 \mathrm{~s}$ measured right after plasma treatment (c) and (d) with plasma treatment time 10 and $60 \mathrm{~s}$ measured 4 days later [38]. 
amplitude of $-4.5 \mathrm{kV}$, the temperature was $20{ }^{\circ} \mathrm{C}$ and the relative humidity was $20 \%$. The results showed that the surface potential decay was slower on the samples measured after 4 days, while the aging resistance of the atmospheric-pressure dielectric barrier discharge (AP-DBD) etching method is not improved significantly.

Based on their previous research results, they further conducted in-depth research on sample modification methods based on plasma treatment in 2017 [39, 40, 43]. They found out that the plasma deposition process can increase the aging resistance more effective than the direct plasma treatment mentioned in their previous work [38]. In their test setup, non-thermal plasma generated by gliding arc discharge driven by high-frequency high-voltage power supply are used to deposit $\mathrm{SiO}_{2}$ film on the surface of epoxy resin, and the reaction precursor is tetraethyl orthosilicate (TEOS) [43]. They realized that when the deposition time exceeded 5s, a thin film with a thickness of $219 \mathrm{~nm}$ containing Si-O-Si and Si-OH groups can be stably formed on the epoxy surface. Meanwhile, with this surface layer, the water contact angle and the surface resistivity were significantly reduced compared with pure epoxy samples, which increases surface charge decay rate significantly [40].

T. Shao et al. further studied the feasibility of plasma deposition on surface charge property and deposited $\mathrm{SiO}_{\mathrm{x}}$ thin film on the surface of epoxy resin by AP-DBD [37, 39]. The results showed that the initial surface charge density was reduced by $12 \%$ and the flashover voltage was increased by $42 \%$ after plasma deposition treatment. They believed that the mechanism for the increasing of these properties is due to the fact that $\mathrm{SiO}_{\mathrm{x}}$ films with a thickness of 50-200 $\mathrm{nm}$ introduce shallow traps, which increases the surface conductivity and thereby reduce the accumulation of surface charges. In 2019, they compared the effect of the three methods of plasma etching, plasma deposition and direct fluorination on the basis of previous researches $[41,42]$. The surface charge decay rate of epoxy based samples after DBD deposition (96\%) and fluorination (95\%) is higher than DBD etching (34\%) [42]. The results from the above mentioned studies indicate that AP-DBD deposition has best performance in increasing the surface charge decay rate of the sample [41].

\subsubsection{Researches in Xi'an Jiaotong University}

D. Min et al. studied the effect of surface plasma treatment on the surface charge decay property of epoxy based composite with different treatment time (1 $\mathrm{min}, 3 \mathrm{~min}, 5 \mathrm{~min})$ [44]. They found out that the surface 
conductivity reaches $1.4 \times 10^{-17} \mathrm{~S}$ which is 2 orders of magnitude higher than that of untreated samples. Meanwhile, the correlation between surface flashover and the surface conductivity showed that the DC surface flashover voltage increases with the increase of the surface conductivity (Figure 12), whose reason they believed was due to the surface charge decay [44].

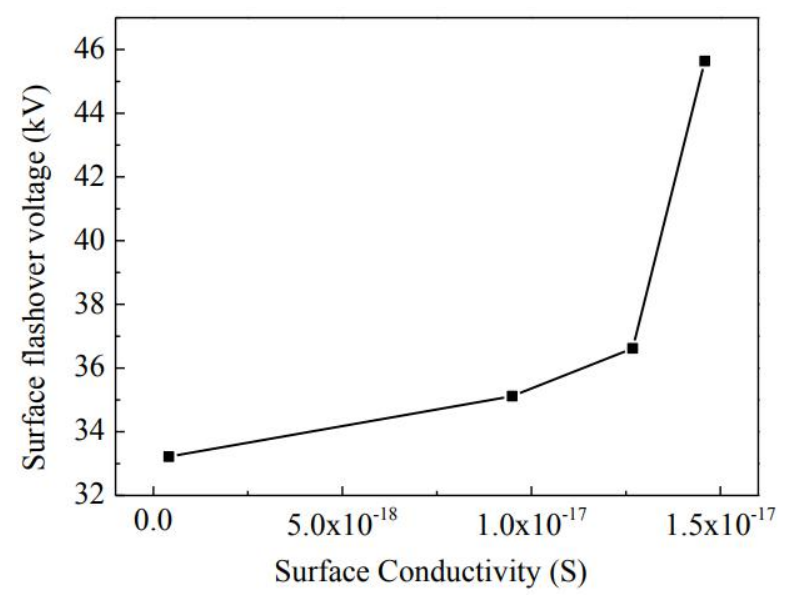

Figure 12. Relation between surface flashover voltage and surface conductivity [44] .

\subsubsection{Analysis and discussion}

Table 3 shows the key parameters selected for each research group according to different treatment methods. Most of the results show an upward trend regarding the surface conductivity of samples after plasma treatment, with the increasing value of 1 to 4 orders of magnitude. However, it is worth noting that contrary to changing laws of surface conductivity after fluorination, the surface conductivity after plasma treatment for 1 minutes is higher than that after treated after 5 minutes. That is to say that the longer the processing time, the higher the surface conductivity will be. Meanwhile, it should be emphasized that DBD deposition methods showed excellent anti-aging performance than AP-DBD [41, 42]. However, the problem regarding forming a uniform discharge to coat the sample surface of large areas ready for industrial applications should be further studied. 
Table 3. Treatment time and results of different plasma processing methods.

\begin{tabular}{|c|c|c|c|c|}
\hline $\begin{array}{l}\text { Research } \\
\text { group }\end{array}$ & Ref. & Treatment type & Processing time & $\begin{array}{c}\text { Surface } \\
\text { conductivity }\left(10^{-18} \mathrm{~s}\right)\end{array}$ \\
\hline \multirow{29}{*}{ T. Shao } & \multirow{6}{*}[43]{} & Untreated & 0 & 1810 \\
\hline & & \multirow{5}{*}{$\begin{array}{l}\text { Plasma enhanced chemical } \\
\text { vapor deposition (PECVD) to } \\
\text { deposit } \mathrm{SiO}_{2} \text { thin films }\end{array}$} & $1 \mathrm{~s}$ & 3810 \\
\hline & & & $3 \mathrm{~s}$ & 6390 \\
\hline & & & $5 s$ & 24100 \\
\hline & & & $10 \mathrm{~s}$ & 85100 \\
\hline & & & $15 \mathrm{~s}$ & 113000 \\
\hline & \multirow{4}{*}[38]{} & Untreated & 0 & 30000 \\
\hline & & \multirow{3}{*}{ AP-DBD etching } & $10 \mathrm{~s}$ & 68000 \\
\hline & & & $60 \mathrm{~s}$ & 190000 \\
\hline & & & $180 \mathrm{~s}$ & 250000 \\
\hline & \multirow{5}{*}[37]{} & Untreated & 0 & 900 \\
\hline & & \multirow{4}{*}{$\begin{array}{l}\text { APPJ Plasma Treatment to } \\
\text { Deposit SiOx Film }\end{array}$} & $1 \mathrm{~min}$ & 9000 \\
\hline & & & $3 \mathrm{mins}$ & 70000 \\
\hline & & & $5 \mathrm{mins}$ & 60000 \\
\hline & & & $10 \mathrm{mins}$ & 30000 \\
\hline & \multirow{4}{*}[42]{} & Untreated & 0mins & 900 \\
\hline & & AP-DBD etching & $5 \mathrm{mins}$ & 7000 \\
\hline & & $\begin{array}{c}\text { AP-DBD Plasma Treatment to } \\
\text { Deposit Ar/TEOS }\end{array}$ & $10 \mathrm{mins}$ & 300000 \\
\hline & & Direct fluorination & $30 \mathrm{mins}\left(\right.$ At $50^{\circ} \mathrm{C}$ ) & 90000 \\
\hline & \multirow{6}{*}{ [41] } & Untreated & 0 & 270.3 \\
\hline & & \multirow{2}{*}{$\begin{array}{c}\text { AP-DBD Plasma Treatment to } \\
\text { Deposit Ar/TEOS }\end{array}$} & $5 \mathrm{mins}$ & 1000000 \\
\hline & & & $10 \mathrm{mins}$ & 1010000 \\
\hline & & \multirow{3}{*}{ Direct fluorination } & $15 \operatorname{mins}\left(\right.$ At $\left.50^{\circ} \mathrm{C}\right)$ & 3330 \\
\hline & & & $30 \operatorname{mins}\left(\right.$ At $\left.50^{\circ} \mathrm{C}\right)$ & 50000 \\
\hline & & & $60 \operatorname{mins}\left(\right.$ At $\left.50^{\circ} \mathrm{C}\right)$ & 100000 \\
\hline & \multirow{4}{*}{ [39] } & Untreated & 0 & 2230 \\
\hline & & \multirow{3}{*}{ AP-DBD deposited SiOx film } & $3 \mathrm{~min}$ & 2000000 \\
\hline & & & $5 \mathrm{mins}$ & 5000000 \\
\hline & & & $10 \mathrm{mins}$ & 54700000 \\
\hline \multirow{4}{*}{ D. Min } & \multirow{4}{*}[44]{} & Untreated & 0 & 0.1 \\
\hline & & \multirow{3}{*}{$\begin{array}{l}\text { HD-1B plasma modification } \\
\text { device }\end{array}$} & $1 \mathrm{~min}$ & 13 \\
\hline & & & $3 \mathrm{~min}$ & 14.5 \\
\hline & & & $5 \mathrm{~min}$ & 10 \\
\hline
\end{tabular}

\subsection{Coatings}

Commonly used coatings to modify surface charge behaviors include: magnetron sputtering coatings, spray coatings, dipping and plasma coatings.

\subsubsection{Research review}

Nano- $\mathrm{TiO}_{2} / \mathrm{EP}$ coatings can increase surface charge decay of epoxy resin, which was developed by $\mathrm{Y}$. Tu et al. [46]. When the content of nano- $\mathrm{TiO}_{2}$ particles is $1 \%$ and $3 \%$, the surface charge is mainly concentrated near the high-voltage electrode while when the content of nano- $\mathrm{TiO}_{2}$ particles is $5 \%$ and $7 \%$, the surface 
charge settles near the grounded electrode. When the particle content is $3 \%$, the surface conductivity reaches a maximum value which is $2 \times 10^{-17} \mathrm{~S}$ [45].

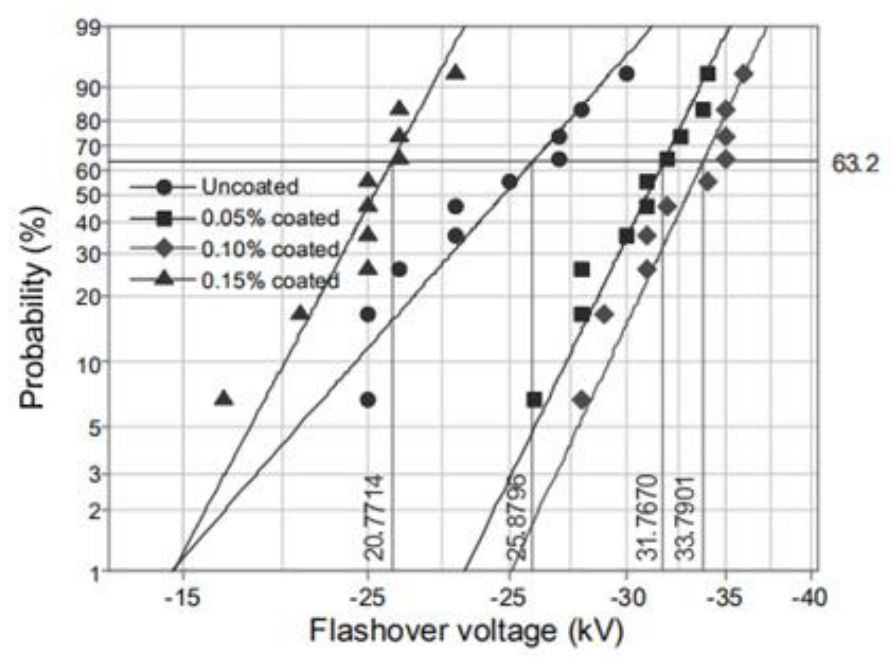

Figure 13. Weibull distributions of flashover voltages of the uncoated and epoxy (EP)/graphene (GR) coated insulators [82].

Meanwhile, B.Du et al. prepared epoxy (EP)/graphene (GR) coated insulators with different doping ratios by dipping and found out that the flashover characteristics of the samples are increased dramatically, as shown in Figure 13 [82]. However, they verified that when the content of nanographene reaches $0.15 \%$, the flashover voltage of EP / GR coated insulators is lower than that of uncoated insulators. They believed that adding of proper nanographene content on the surface layer increases the trapping energy and density of EP / GR composites; thereby the surface charge decay rate of the insulator is increased.

G.Zhang et al. proposed a structurally nacre-mimetic coating on epoxy insulators achieved by using a facile flow-induced co-assembly technique. By doing so, a faster charge dissipation and higher surface flashover voltage were observed, as shown in Figure 14 [83].
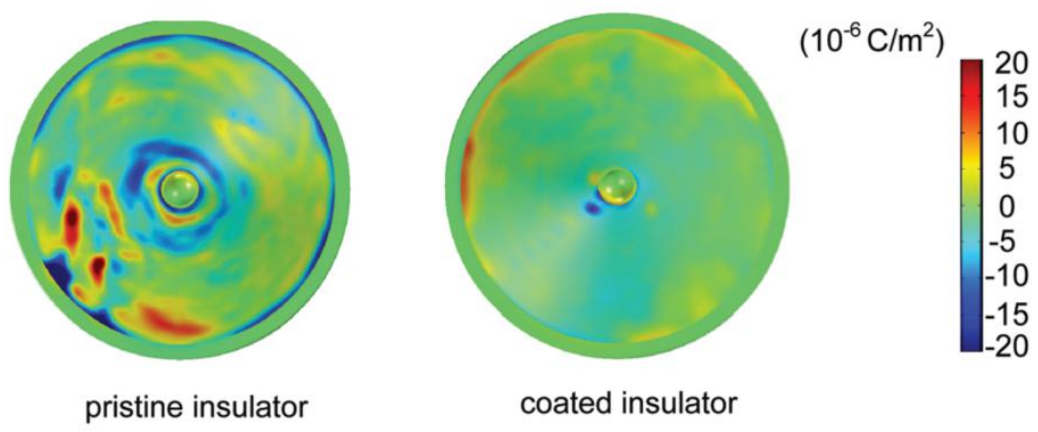

Figure 14. Surface charge density distribution on cone-type insulators after application of a $-20 \mathrm{kV} d c$ voltage for 30 minutes [83]. 


\subsubsection{Analysis and discussion}

Table 4 summarized the feature parameters regarding epoxy coatings in the above mentioned research groups. In addition to the parameters researches focusing on after fluorination or plasma treatment, i.e. surface conductivity and surface roughness, these two research groups attempt to explain charge tailoring mechanism by introducing the charge carrier mobility. Y. Tu et al observed that, the carrier mobilities of the coatings, with $1 \mathrm{wt} \%$ and $3 \mathrm{wt} \%$ micro-SiO 2 particles, reach as high as $11 \times 10^{-13} \mathrm{~m}^{2} /(\mathrm{V} \cdot \mathrm{s})$ and $17.5 \times 10^{-13} \mathrm{~m}^{2} /(\mathrm{V} \cdot \mathrm{s})$, while the carrier mobility introduced by nano- $\mathrm{SiO}_{2}$ particle composite coatings with a doping amount of $3 \mathrm{wt} \%$ is the highest around $86 \times 10^{-13} \mathrm{~m}^{2} /(\mathrm{V} \cdot \mathrm{s})$. The above three samples have been verified effectively to inhibit the accumulation of surface charges on epoxy resins. However, in the study conducted by B. Du et al, the $0.1 \mathrm{wt} \%$ nanographene / EP composite coating results in a DC flashover voltage of up to $33 \mathrm{kV}$, while the carrier mobility of this sample shows the lowest value around $0.14 \times 10^{-13} \mathrm{~m}^{2} /(\mathrm{V} \cdot \mathrm{s})$ compared with other samples. However, the carrier mobility of the samples in [45] is 2 orders of magnitude higher than that in [82]. Therefore, it can be assumed that the carrier mobility can only be used as an auxiliary basis for explaining surface flashover voltage, while other factors such as the coating material intrinsic property, surface morphologies, etc. need to be comprehensively evaluated. The dominant factors to determine the effectiveness of surface charge controlling methods on insulators need to be further explored. In addition, the anti-aging property of the coating and its stability against the cold and heat cycles still need further consideration, which also greatly limits the industrialization of such coatings methods.

Table 4. Relationship between Carriers and Doping Amount of Different Coating Materials.

\begin{tabular}{|c|c|c|c|c|c|c|}
\hline $\begin{array}{l}\text { Research } \\
\text { group }\end{array}$ & No./ref & Coating material & $\begin{array}{l}\text { The average } \\
\text { particle size of the } \\
\text { coating doped } \\
\text { particles } 10^{-9} \mathrm{~m}\end{array}$ & $\begin{array}{c}\text { Coating } \\
\text { thickness } \\
10^{-6} \mathrm{~m}\end{array}$ & $\begin{array}{c}\text { Coating doping } \\
\text { content } \\
\text { wt } \%\end{array}$ & $\begin{array}{c}\text { Carrier } \\
\text { mobility } \\
10^{-13} \mathrm{~m}^{2} /(\mathrm{V} \cdot \mathrm{s})\end{array}$ \\
\hline \multirow{7}{*}{ Y. Tu } & \multirow{4}{*}{ [45] } & \multirow{4}{*}{$\begin{array}{l}\text { Nano-SiO } / \text { EP composite } \\
\text { coating }\end{array}$} & \multirow[t]{4}{*}{1} & \multirow{7}{*}{$170-190$} & 0 & 7 \\
\hline & & & & & 1 & 5.2 \\
\hline & & & & & 3 & 86 \\
\hline & & & & & 5 & 30 \\
\hline & \multirow{3}{*}[45]{} & \multirow{3}{*}{$\begin{array}{c}\text { Micron } \mathrm{SiO}_{2} / \mathrm{EP} \text { composite } \\
\text { coating }\end{array}$} & \multirow{3}{*}{700} & & 1 & 11 \\
\hline & & & & & 3 & 17.5 \\
\hline & & & & & 5 & 9.5 \\
\hline \multirow{4}{*}{ B. Du } & \multirow{4}{*}{ [82] } & \multirow{4}{*}{$\begin{array}{l}\text { Nanographene / EP composite } \\
\text { coating }\end{array}$} & \multirow{4}{*}{$500-5000$} & \multirow{4}{*}{$\begin{array}{c}\text { Not } \\
\text { mentioned }\end{array}$} & 0 & 0.38 \\
\hline & & & & & 0.05 & 0.18 \\
\hline & & & & & 0.1 & 0.14 \\
\hline & & & & & 0.15 & 0.46 \\
\hline
\end{tabular}

3.4. Other methods 
In addition to the methods already mentioned, the following techniques are also discussed by researchers as candidates to modify surface charge behaviors, which includes: gamma ray treatment, roughness treatment, ozone treatment, and radical scavenger treatment.

\subsubsection{Gamma rays}

In 2010, Y. Gao et al. found that the surface charge decay rate of epoxy insulator is accelerated after epoxy sample being treated by gamma rays, and the surface potential decay rate shows the best results when using the $1000 \mathrm{kGy}$ irradiated sample $[47,48]$. They attributed the increased charge dissipation to the decrease in trap depth.

\subsubsection{Surface roughness treatment}

In 1983, Nakaishi K et al. found that unpolished cylindrical insulators present a "bow-tie" like surface charge distribution under DC voltage(as shown in Figure 15), and the surface charge uniformly distributes when the surface is polished, believed to be attributable to the increase in conductivity after grinding[58].

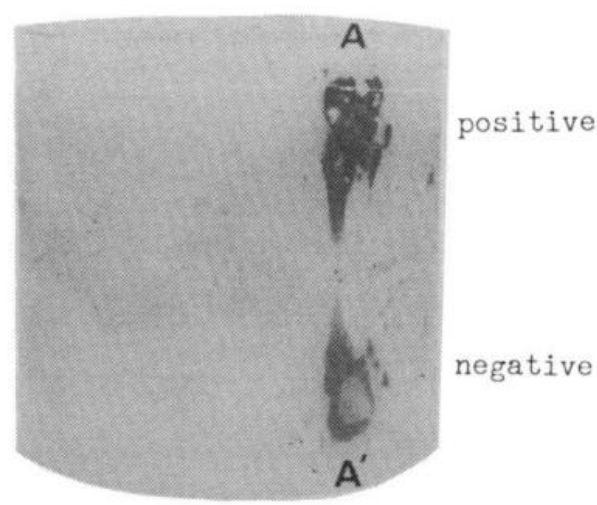

(a)

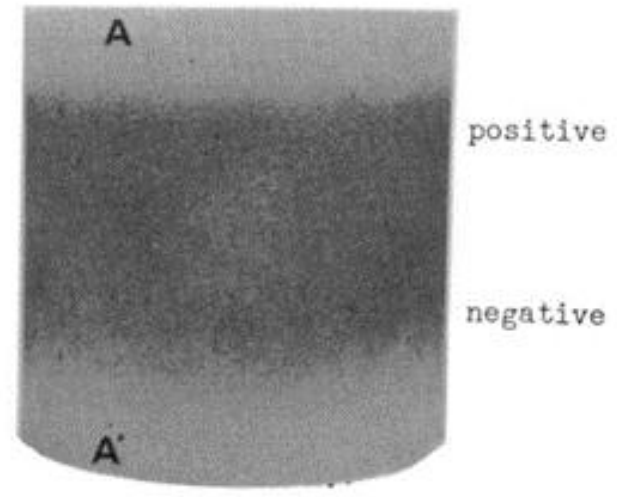

(b)

Figure 15. Probe measurement of residual charge distribution on the spacer. (a) The untreated sample,(b) The sanded sample [58].

Kumada et al. conducted similar work to change the surface smoothness of the conical epoxy insulator with sandpaper. They found lower surface charge density in the polished areas, but a large amount of charges 
accumulate at the junction of the polished and unpolished areas, as shown in Figure 16. Based on such findings, they believed that the uneven conduction on the insulator surface is the cause of the surface charge accumulation [84].

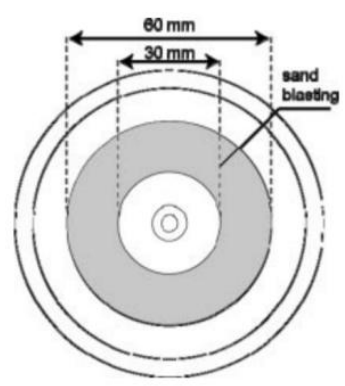

(a)
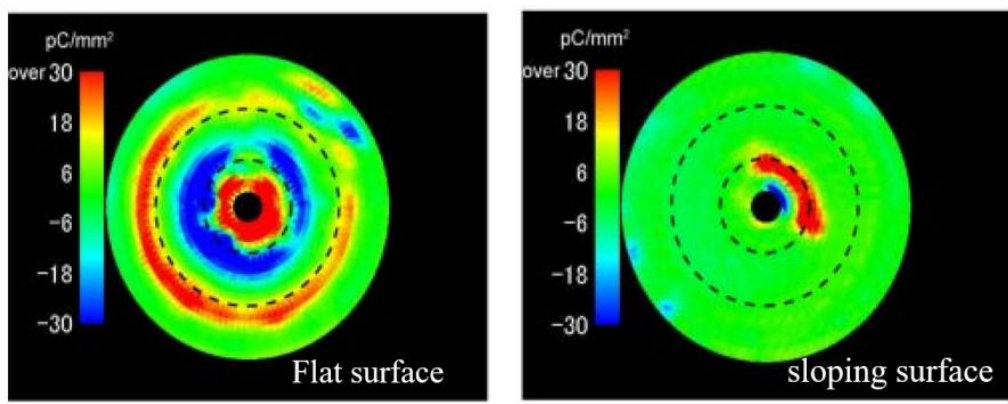

(b)

Figure 16. (a) Sand blasted region on the spacer. (b) Charge distribution after 240 hours' voltage application for the spacer with nonuniform surface conductivity [84].

Further, J. Xue et al. studied the surface charging property and surface flashover characteristics in $\mathrm{SF}_{6} / \mathrm{N}_{2}$ mixed systems using epoxy alumina insulator samples with different surface roughness [85]. Under positive DC voltage, the average surface flashover voltages for samples with surface roughness of $0.58 \mu \mathrm{m}, 5.19 \mu \mathrm{m}$, $7.48 \mu \mathrm{m}$, and $9.24 \mu \mathrm{m}$ were $15.48 \mathrm{kV}, 16.24 \mathrm{kV}, 16.76 \mathrm{kV}$, and $17.55 \mathrm{kV}$, respectively. Compared with the untreated surface $(0.58 \mu \mathrm{m})$, the positive DC voltage increased by $4.86 \%(5.19 \mu \mathrm{m}), 8.27 \%(7.48 \mu \mathrm{m})$, and $13.32 \%(9.24 \mu \mathrm{m})$, respectively (as shown in Figure 17). The DC flashover voltage can be increased by $20 \%$ to $25 \%$ after the surface is roughened. They believed that the increase in surface flashover voltage firstly is mainly due to the increase in the leakage distance caused by surface treated roughness and blockage. Secondly, the surface conductivity was decreased slightly, but it was still higher than untreated sample. At the same time, the introduced deep traps would also inhibit the surface charge accumulation, increase the insulation strength, and increase the corresponding flashover voltage. It is concluded that the surface roughness treatment can suppress the surface charge accumulation and improve the surface flashover voltage. 


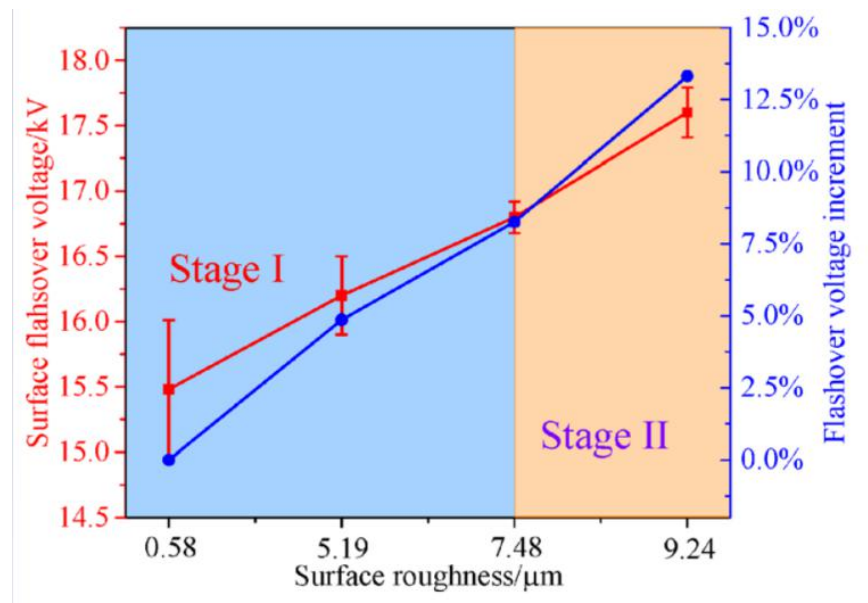

Figure 17. Surface flashover performance on spacer with different amount of surface roughness under positive DC voltage stress [85].

\subsubsection{Ozone treatment}

The effect of ozone treatment on the surface flashover performance of epoxy $/ \mathrm{Al}_{2} \mathrm{O}_{3}$ composite was studied and the results showed that the surface conductivity by ozone treatment for $4 \mathrm{~h}$ is increased by 2 orders of magnitude compared with the untreated sample, as shown in Figure 18 [49]. The density of shallow traps increases with the increase of treatment time, while the energy of shallow surface traps decreases with the increase of treatment time. Authors believed that the change in these two parameters simultaneously increases the charge carrier of the sample and increases the surface charge dissipation rate.

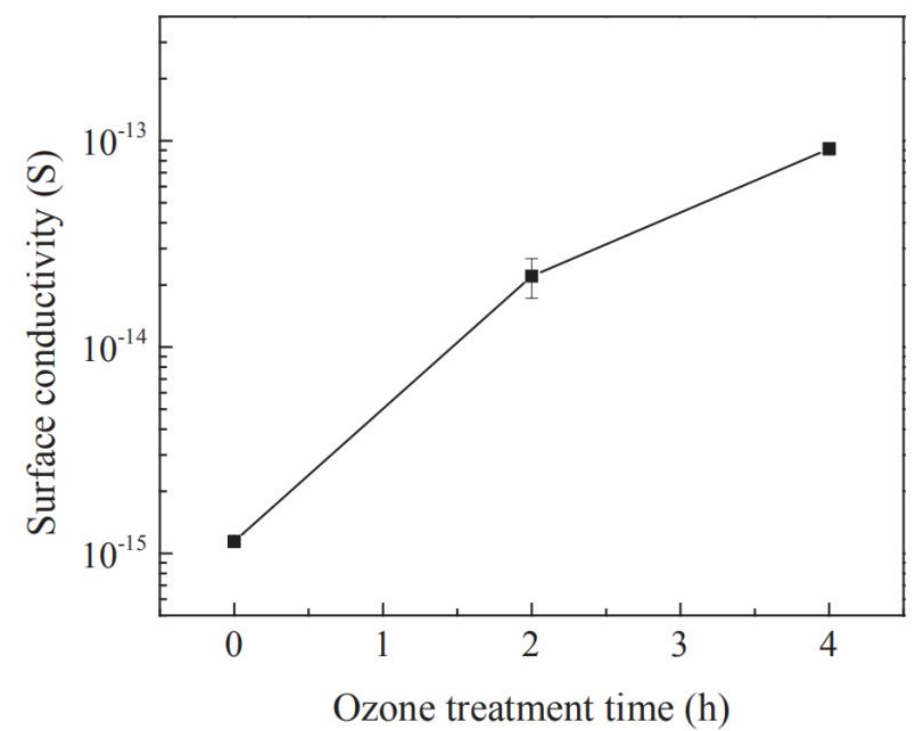

Figure 18. Surface conductivity of epoxy resin micro-composites before and after ozone surface treatment [49].

\subsubsection{Radical scavenger}


In 2013, H. Tarik Baytekin et al. proposed that scavenging for free radicals from surface could be a more efficient way to increase surface charge decay rate, than controlling the surface charges itself [50]. They argued that these free radicals coexist with the charge and stabilize them on the surface. When they are cleared, the surface discharge occurs faster.
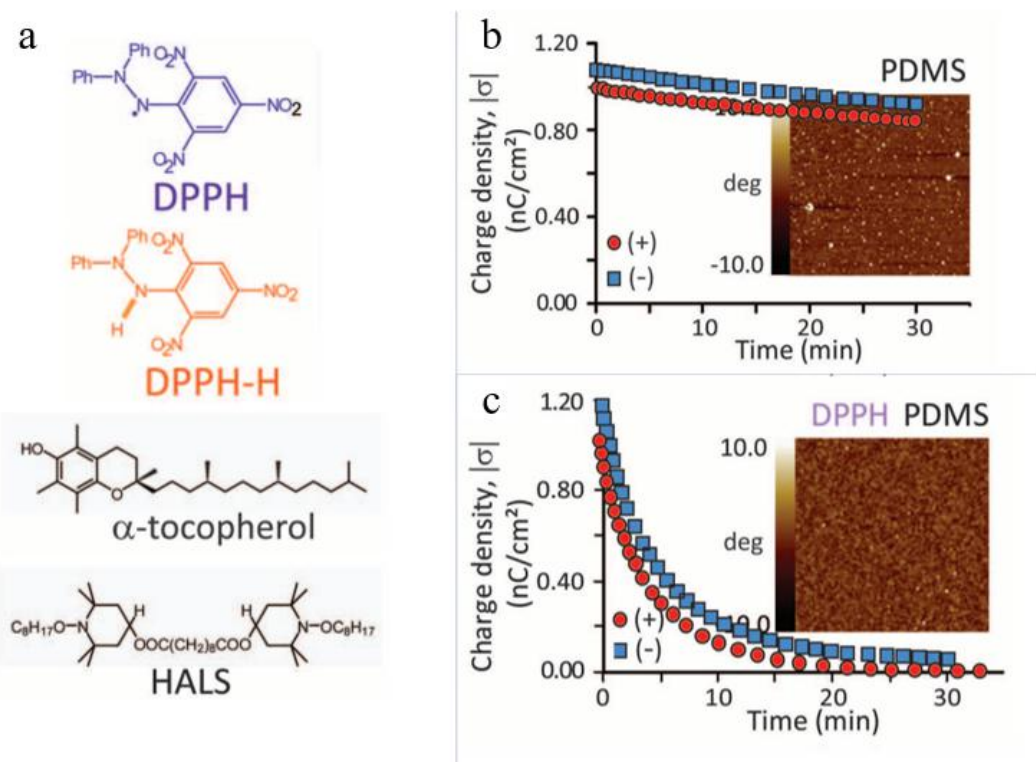

Figure 19. (a) Four kinds of radical scavengers; (b) charge decay of pure PDMS charged by corona discharge either $(+)$ or $(-)$, and free radicals(white spots) distribution of different samples in 30 minutes;(c) charge decay of PDMS/5 mM DPPH charged by corona discharge either $(+)$ or $(-)$, and free radicals(white spots) distribution of different samples in 30 minutes [50].

They performed a series of charging experiments with native polymers, as well as polymers doped with small amounts of chemical substances scavenging the radicals such as (as shown in Figure 19 (a))(T)-a-tocopherol (vitamin E), bis(1-octyloxy-2,2,6,6-tetramethyl-4-piperidyl) sebacate (HALS), 2,2-diphenyl-1-picrylhydrazyl (DPPH) or 2,2-diphenyl-1-picryl hydrazine (DPPH-H), and the results showed that the presence of free radical scavengers reduced the tendency of the polymer to generate static electricity effectively during contact charging. Figure 19 (b) and (c) show that under the corona discharge, the surface charge attenuation of the sample with added DPPH, is significantly higher than that of the original sample.

However, this radical scavenger approach may not work for thermosetting materials such as epoxy resins. We performed similar researches using astaxanthin, which serves as a strong oxidant, to treat epoxy based materials. The results showed that a good level of charge dissipation can only be found in samples just after treatment, and this charge dissipation ability gradually decreases with time. After storage for 24 hours in air 
and in $\mathrm{SF}_{6}$, we found that the surface potential decay rate becomes invalid with the same charge decay rate as that of the untreated samples (as shown in Figure 20).

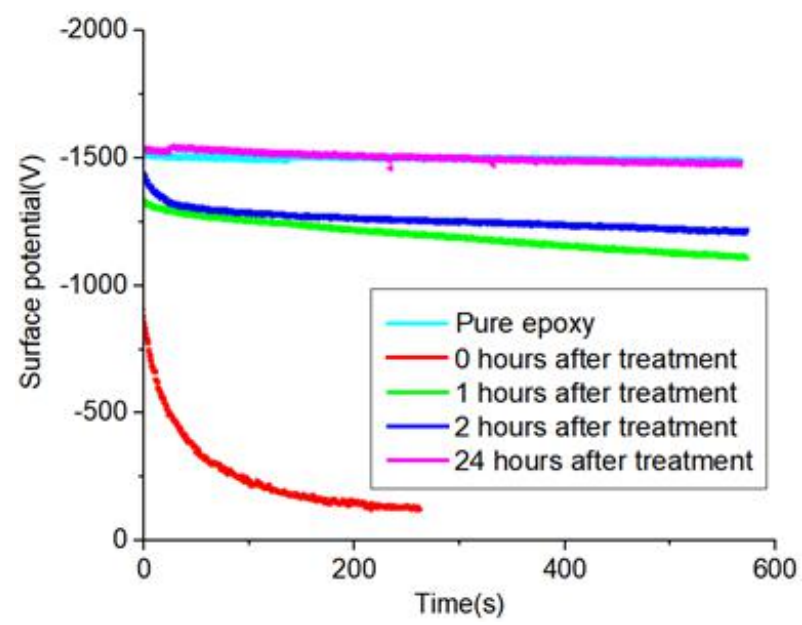

Figure 20. Epoxy surface potential decay curve of epoxy resin treated with astaxanthin and stored at 0.1 $\mathrm{MPa} \mathrm{SF}_{6}$ for different certain times (Soak for 10 minutes, test after drying).

The charging mechanism of contact electrification-(triboelectrification) and electrification due to electric fields or corona are very different from each other. One involves material transfer, surface oxidation, reorientation of polar molecules; however the other involves mainly oxidation and may be reorientation. The impact of specific physical or chemical reaction processes on this event needs further research. In addition, in H. Tarik Baytekin 's study, they used PDMS, an elastomer with very low Tg, and molecules or chains were very active at the surface (and also in the volume) at the room temperature. For this reason, antioxidant molecules could find the active groups easily at the surface, and discharg occured rapidly. Epoxy may not have these characteristics.

\subsubsection{Analysis and discussion}

Table 5 shows the results obtained from different treatment methods in this section. It can be found from [85] and [49] that compared with the roughness treatment that can increase surface conductivity by 1 order of magnitude, the ozone treatment effectively increases surface conductivity of nearly 2 orders of magnitude after treating the sample for $2 \mathrm{~h}$. Meanwhile, the increase ratio of the flashover voltage of samples by different treatments shows that the surface flashover voltage of the treated sample by roughness method was increased by $13.37 \%$, while the surface flashover voltage of the ozone-treated samples is increased by $20.93 \%$. It should 
be noted that due to the differences in samples and experimental setup, it would be difficult to make comparisons regarding surface flashover properties.

The radical scavenger treatment method uses the coexistence of these free radicals to achieve the purpose of eliminating charges indirectly by eliminating free radicals. However, for the radical elimination mechanism of epoxy based samples, more studies should be carried out. Meanwhile, the aging behavior and anti-aging property should be more important while dealing with products in industrial applications. Gamma ray shows very good property in surface charge decay rate. However, such methods are complicated and might threaten the human health if not been controlled properly. Besides, g-ray produces homogeneous modification of the material, meaning that both surface and volume leakage should be modified. The treatment may have detrimental effects to bulk insulation.

Table 5. Modification methods and corresponding results of each research group.

\begin{tabular}{|c|c|c|c|c|c|c|}
\hline \multirow[b]{2}{*}{$\begin{array}{l}\text { Research } \\
\text { group }\end{array}$} & \multirow[b]{2}{*}{ No./ref } & \multirow[b]{2}{*}{$\begin{array}{l}\text { Treatment } \\
\text { method }\end{array}$} & \multirow[b]{2}{*}{ Parameter } & \multicolumn{3}{|c|}{ Result } \\
\hline & & & & $\begin{array}{c}\text { Surface } \\
\text { conductivity } \\
10^{-18} \mathrm{~S} / \mathrm{m}\end{array}$ & $\begin{array}{c}\text { Surface potential } \\
\text { decay ratio } \\
\text { (at 1000s) }\end{array}$ & $\begin{array}{c}\text { Flashover voltage } \\
\mathbf{k V} \\
\text { (Increasing rate) }\end{array}$ \\
\hline \multirow{3}{*}{ Y. Gao } & \multirow{3}{*}[47]{} & \multirow{3}{*}{$\begin{array}{l}\text { gamma-ray } \\
\text { irradiation }\end{array}$} & Untreated & & $7 \%$ & \\
\hline & & & 100kGy irradiation & & $10 \%$ & \\
\hline & & & 1000kGy irradiation & & $15 \%$ & \\
\hline \multirow{4}{*}{ J. Xue } & \multirow{4}{*}[85]{} & \multirow{4}{*}{$\begin{array}{l}\text { Surface } \\
\text { roughness } \\
\text { treatment }\end{array}$} & Roughness:0.58 $\mu \mathrm{m}$ & 5.8 & & 15.5 \\
\hline & & & 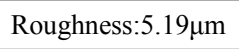 & 80.6 & & $16.2(+4.91 \%)$ \\
\hline & & & Roughness:7.48 $\mu \mathrm{m}$ & 99.0 & & $16.8(+8.27 \%)$ \\
\hline & & & 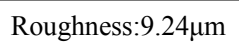 & 22.3 & & $17.6(+13.37 \%)$ \\
\hline \multirow{3}{*}{ D. Min } & \multirow{3}{*}{ [49] } & \multirow{3}{*}{$\begin{array}{l}\text { Ozone } \\
\text { treatment }\end{array}$} & Untreated & 1100 & $20 \%$ & 21.5 \\
\hline & & & Processing $2 \mathrm{~h}$ & 25000 & $100 \%$ & $24.7(+14.88 \%)$ \\
\hline & & & Processing $4 \mathrm{~h}$ & 90000 & $100 \%$ & $26.0(+20.93 \%)$ \\
\hline
\end{tabular}

\section{Dam reinforcement-suppressing charge from volume conduction and gas ionization}

In order to decrease the conduction current from the volume, manners of coating or doping are usually used, while coating on the conductor surface and/or smoothing the conductor surface both can decrease micro discharge and thereby limit charges from gas ionization.

\subsection{Suppressing charge from volume conduction current}

In order to suppress charge from the volume, we focus on the metal/insulation interface as well as the bulk property. 


\subsection{1 $\mathrm{Cr}_{2} \mathrm{O}_{3}$ coating}

A dense, ordered $\mathrm{Cr}_{2} \mathrm{O}_{3}$ nano-coating created by the magnetron sputtering method on the epoxy surface was verified as a good way to restrain charge injection from metal/insulation interface, which is due to deep traps introduced by the coating $[33,51]$. The effect of fluorination, plasma treatment, and $\mathrm{Cr}_{2} \mathrm{O}_{3}$ coating on charge suppression property using epoxy samples were compared and results showed that the $\mathrm{Cr}_{2} \mathrm{O}_{3}$ coating has the best charge injection suppression behavior, followed by surface fluorination as shown in Figure 21 [33].

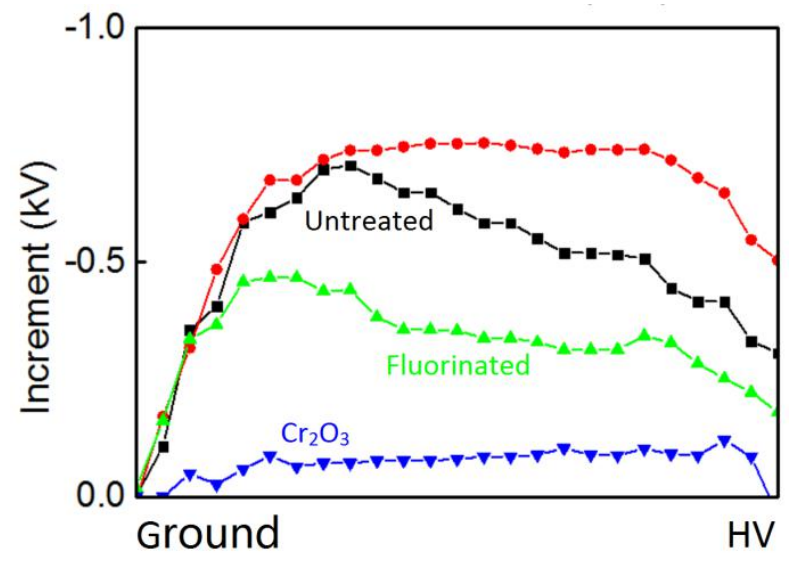

Figure 21. Surface potential increment from $0.5 \min$ to $2 \min [33]$.

\subsubsection{Nano-doping}

Z. Zhang et al. verified that surface-modified silica nanoparticles can be used to suppress the leakage current of epoxy [86]. Figure 22 presents the variation of volume conductivity ( $\rho v$ ) of epoxy nanocomposites with different filler fraction and the results show that for the non-linear change of the volume conductivity ( $\rho v)$ of the alkyl-modified nanoparticles with the proportion of filler, the maximum $\rho v$ value is obtained at a low filling fraction $(1 \mathrm{wt} \%)$. They believed that the effect of the volume resistivity on the surface modification of nanoparticles can be attributable to two possible reasons: (1) Low-polarity nanoparticles have a large number of highly insulating alkyl groups and a small number of hydroxyl groups and / or absorbed water molecules (that is, charge carriers (ions) that increase conductivity under an electric field); (2) Surface modification changes the Maxwell-Wagner-Sillars polarization behavior of the composite material, thereby affecting the electrical conductivity of the composite material. 


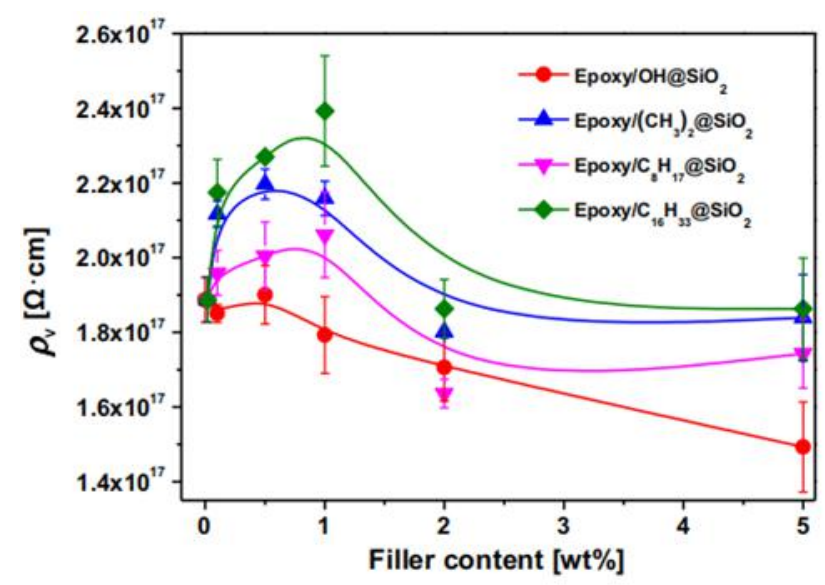

Figure 22. The volume resistivity ( $\rho v)$ of epoxy and epoxy nanocomposites at room temperature $\rho v-$ filler fraction curves [86].

G. Zhang et al. introduced different contents of Buckminster-fullerene $\mathrm{C}_{60}$ into epoxy resin to limit the mobility of charge carriers in the material [52]. They found that the electrical conductivity of $100 \mathrm{ppm} \mathrm{C}_{60} /$ epoxy composite decreases dramatically with a value of $1.0 \times 10^{-18} \mathrm{~S} / \mathrm{cm}$, which does not exceed $20 \%$ of the conductivity for pure epoxy resin. They believe that deep traps introduced are responsible for the inhibition of charge injection.

The above mentioned studies focused on methods to suppress charge injection. However, S. He et al. focused on restraining the charge transport inside the bulk by doping $\mathrm{K}_{2} \mathrm{Ti}_{6} \mathrm{O}_{13}$ whiskers into epoxy based material [53]. They took advantage of the thermal barrier effect of $\mathrm{K}_{2} \mathrm{Ti}_{6} \mathrm{O}_{13}$ whiskers to suppress the transport of homo-polar charges in the bulk, and the result demonstrate that the introducing the $\mathrm{K}_{2} \mathrm{Ti}_{6} \mathrm{O}_{13}$ whiskers can effectively restrain heat propagation due to its excellent thermal barrier property, which in turn limits charge transport effectively, especially at temperature gradient.

\subsubsection{Analysis and discussion}

It has been shown that $\mathrm{C}_{60}$ and $\mathrm{SiO}_{2}$ nano-fillers can reduce the sample volume conductivity. As shown in the Table 6, the best property of epoxy samples are obtained when the doping amounts of the $\mathrm{C}_{60}$ nano-filler and $\mathrm{SiO}_{2}$ filler are $100 \mathrm{ppm}$ and $1 \%$, respectively. However, compared with doping of $\mathrm{C}_{60}$ and $\mathrm{SiO}_{2}$, the doping with $\mathrm{K}_{2} \mathrm{Ti}_{6} \mathrm{O}_{13}$ whisker takes advantage of its thermal barrier effect in effectively prevent the diffusion of heat under condition of temperature gradient. 
Table 6. Modification methods and corresponding volume conductivity of each research group.

\begin{tabular}{|c|c|c|c|c|c|c|}
\hline $\begin{array}{l}\text { Research } \\
\text { group }\end{array}$ & Ref. & $\begin{array}{l}\text { Processing } \\
\text { method }\end{array}$ & Sample composition & $\begin{array}{c}\text { Ambient } \\
\text { temperature } \\
{ }^{\circ} \mathrm{C}\end{array}$ & $\begin{array}{l}\text { Doping } \\
\text { amount }\end{array}$ & $\begin{array}{l}\text { Volume conductivity } \\
\qquad 10^{-16} \mathrm{~S} / \mathrm{m}\end{array}$ \\
\hline \multirow{5}{*}{ Z. Zhang } & \multirow{5}{*}[86]{} & \multirow{5}{*}{ Nano-doping } & \multirow{5}{*}{ Epoxy $/ \mathrm{C}_{16} \mathrm{H}_{33} @ \mathrm{SiO}_{2}$} & \multirow{5}{*}{20} & 0 & 5.26 \\
\hline & & & & & 0.5 & 4.39 \\
\hline & & & & & $1 \%$ & 4.167 \\
\hline & & & & & $2 \%$ & 5.29 \\
\hline & & & & & $5 \%$ & 5.21 \\
\hline \multirow{7}{*}{ G. Zhang } & \multirow{7}{*}[52]{} & \multirow{7}{*}{ Nano-doping } & \multirow{7}{*}{ Epoxy $/ \mathrm{C}_{60}$} & \multirow{7}{*}{$20-25$} & 0 & 6.1 \\
\hline & & & & & $1 \mathrm{ppm}$ & 4 \\
\hline & & & & & $10 \mathrm{ppm}$ & 2.7 \\
\hline & & & & & $24 \mathrm{ppm}$ & 2.2 \\
\hline & & & & & $100 \mathrm{ppm}$ & 1.0 \\
\hline & & & & & $200 \mathrm{ppm}$ & 1.2 \\
\hline & & & & & $1000 \mathrm{ppm}$ & 6.9 \\
\hline \multirow{3}{*}{ S. He } & \multirow{3}{*}{ [53] } & \multirow{3}{*}{$\begin{array}{l}\text { Micron } \\
\text { doping }\end{array}$} & Epoxy $/ \mathrm{Al}_{2} \mathrm{O}_{3}$ & \multirow{3}{*}{$12-14$} & 0 & 58.48 \\
\hline & & & Epoxy $/ \mathrm{Al}_{2} \mathrm{O}_{3} / \mathrm{K}_{2} \mathrm{Ti}_{6} \mathrm{O}_{13}$ & & $10 \%$ & 96.15 \\
\hline & & & Epoxy $/ \mathrm{Al}_{2} \mathrm{O}_{3} /$ asbestos & & $10 \%$ & 44444.4 \\
\hline
\end{tabular}

\subsection{Suppressing charge from gas phase}

The electric field at the micro-protrusions on the rough electrode surface can be enhanced to a level under which micro-discharge will take place. Controlling the surface roughness of electrodes can effectively suppress the source of charge generated by the micro-discharge from the gas phase [87-89]. Figure 23 shows stabilized currents measured in both polarities with respect to electric field ranging from 2 to $30 \mathrm{kV} \cdot \mathrm{mm}^{-1}$, with electrodes $\mathrm{A}, \mathrm{B}$, and $\mathrm{C}$, and fixed gas condition $\left(0.6 \mathrm{MPa}, 20{ }^{\circ} \mathrm{C}, \mathrm{RH} \approx 30 \%\right)$ [88]. In both polarities, currents are strongly influenced by the high voltage electrode roughness, with a two orders of magnitude difference between electrodes (A) and (C). 


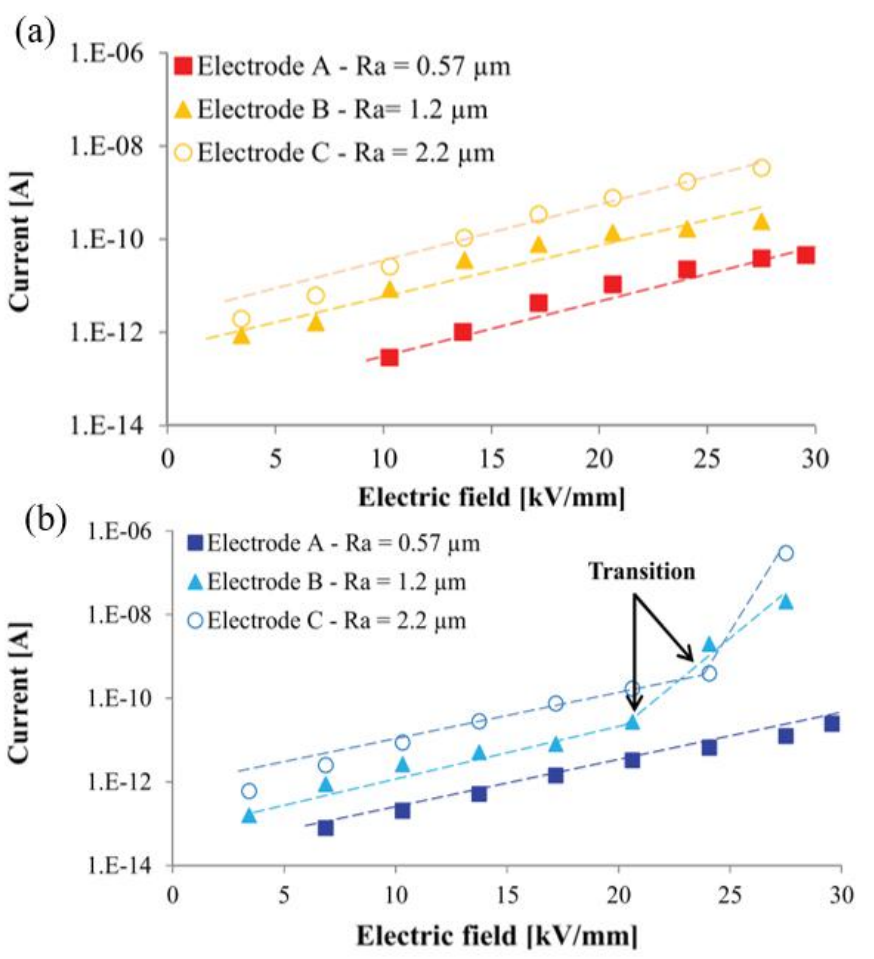

Figure 23. Current measured in $\mathrm{SF}_{6}$, versus electric field for three different electrode roughnesses, (0.6MPa, $20{ }^{\circ} \mathrm{C}, \mathrm{RH} \approx 30 \%$ ) (a) in positive polarity; (b) in negative polarity [88].

\section{Dredging-local electric field modification}

Dredging is a commonly used approach to increase the canal depth and therefore increase the capacity of canals for carrying water. With respects to spacers, by means of material modification and shape controlling, local electric field can be optimized and the flashover withstand voltage of the spacer can thereby be increased. To achieve this goal, nonlinear materials are usually adopted to modify the local electric field, and shape modification of insulators can also be a good way to optimize local electric fields.

\subsection{Nonlinear Conductive composite}

In 1999, F. Messerer et al. coated dupont conductive powder which contains titanium oxide and tin oxide on the surface of epoxy resin. They found that the maximum value of the electric field on the surface of the insulator is reduced from $36.7 \mathrm{kV} / \mathrm{cm}$ to $29.6 \mathrm{kV} / \mathrm{cm}$ under the DC voltage of $100 \mathrm{kV}$ after coating on a cylindrical sample of polyethylen with a diameter of $2 \mathrm{~cm}$ [90]. When the surface conductivity of the insulator is increased to $10^{-11}-10^{-12} \mathrm{~S}$, the electric field distribution on the surface of the insulator can be effectively improved [91]. Based on the preliminary conclusion on electric field optimization taking advantage of 
distributed conductivities, nonlinear conductivity composites, which have nonlinear behavior with respect to the electric field, are considered by researchers worldwide. This chapter mainly reviews the application of nonlinear materials in the modification of local electric fields.

\subsubsection{Bulk doping}

In 2013, M. Tenzer et al. proposed an insulator using oriented “MFF (Minatec ${ }^{\circ}$ functional filler)" filler $[92,93]$. These commercially available particles are flake-shaped mica pigments, covered by a thin tin oxide layer doped with antimony and titanium dioxide. Figure 24(a) shows that such MFF-doped epoxy composites have good nonlinear conductivity properties related to electric field strength [94]. Meanwhile, the electric field distribution of MFF-doped insulators presented in Figure 24 (b) shows a more uniform electric field distribution on the surface under the effect of room temperature and temperature gradient than the traditional spacer.

(a)

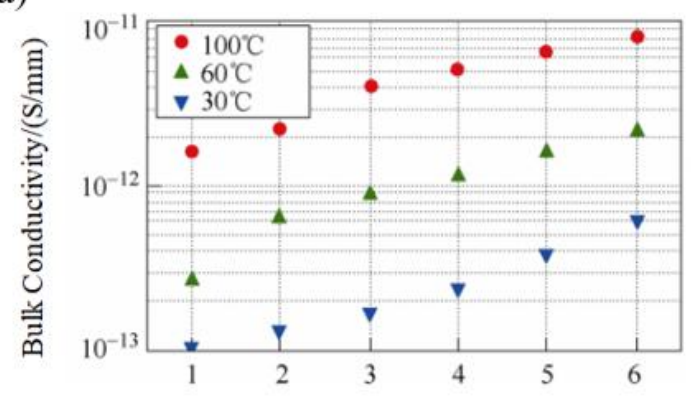

(b) Electric Fields $/(\mathrm{kV} / \mathrm{mm})$

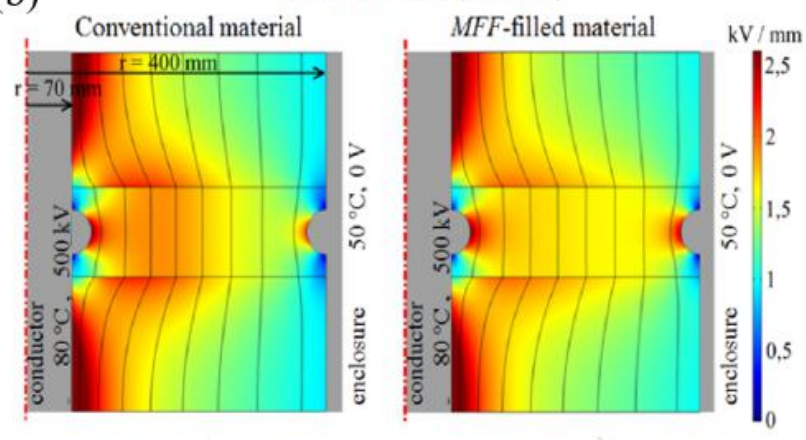

Figure 24. (a) Bulk conductivity of MFF-doped epoxy under different electric fields and temperatures [94];(b) Electric field distribution of conventional insulator and MFF-filled insulator [92].

B. Du et al. studied effect of $\mathrm{SiC}$ particles on electrical characteristics $[63,65]$ and the results showed that with the increase of the filler content, the threshold value of nonlinear conductivity has a downward trend, 
with their values of $8,2.8$ and $2 \mathrm{kV} / \mathrm{mm}$ for samples with doping ratios of 3,10 and $14 \mathrm{vol} \%$ as shown in Figure 25(a) [63]. They further found that with the increase of temperature, the flashover voltage of untreated samples becomes higher than SiC-doped samples, as shown in Figure 25 (b), (c) and (d) [65].

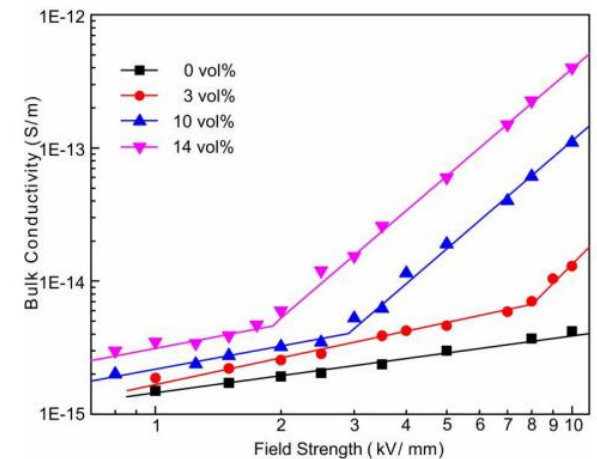

(a)

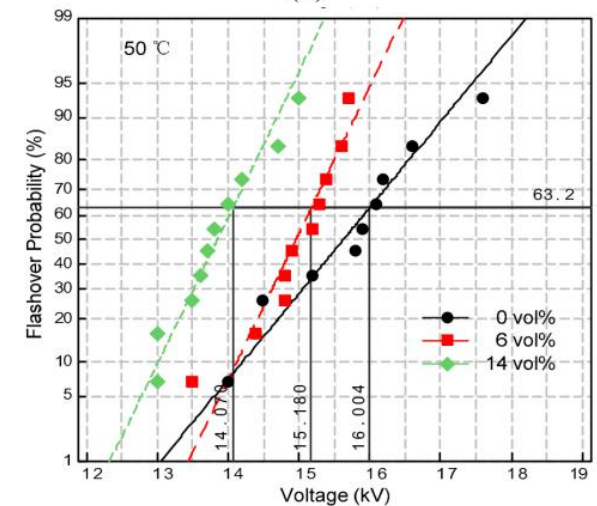

(c)

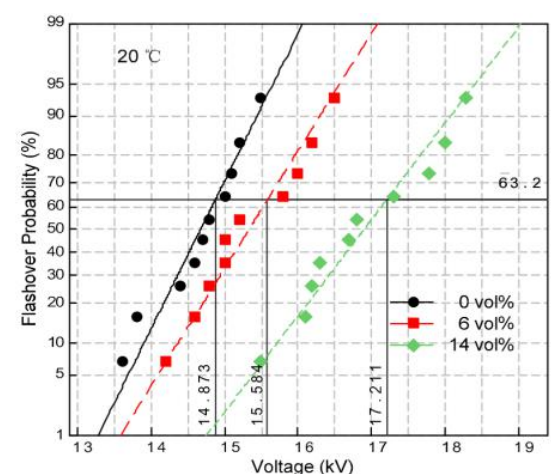

(b)

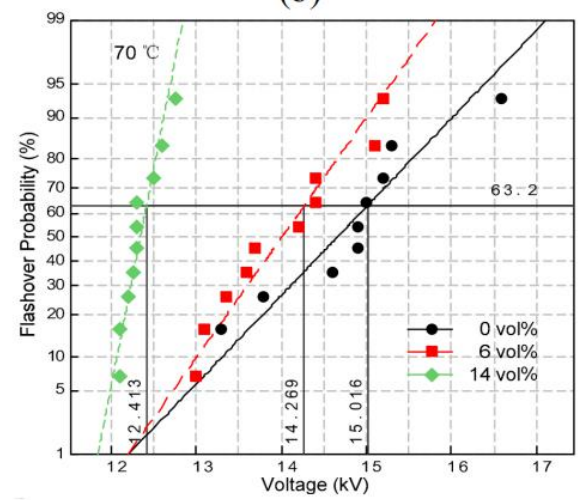

(d)

Figure 25. (a) Relation between the bulk conductivity and the electric field strength [63], (b) the flashover voltages of samples with different filler contents at $20^{\circ} \mathrm{C}$, (c) the flashover voltages of samples with different filler contents at $50^{\circ} \mathrm{C}$, and (d) the flashover voltages of samples with different filler contents at $70^{\circ} \mathrm{C}$ [65].

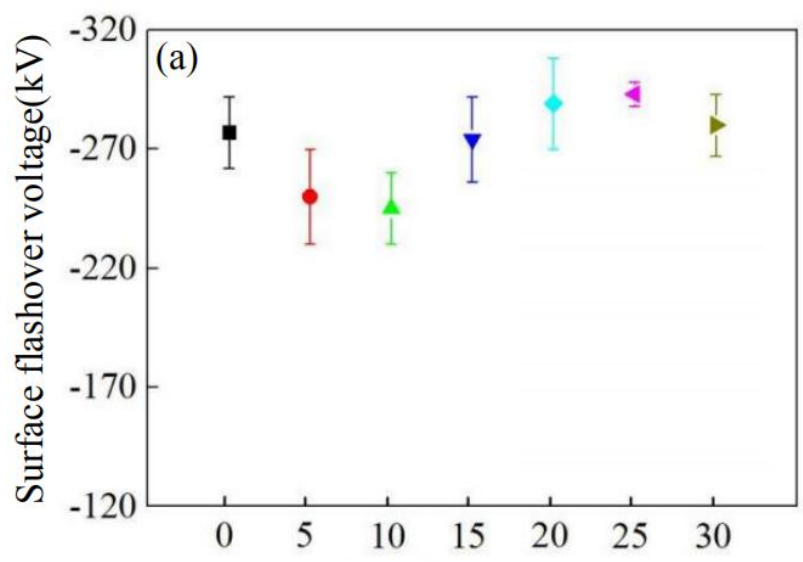

Filler content

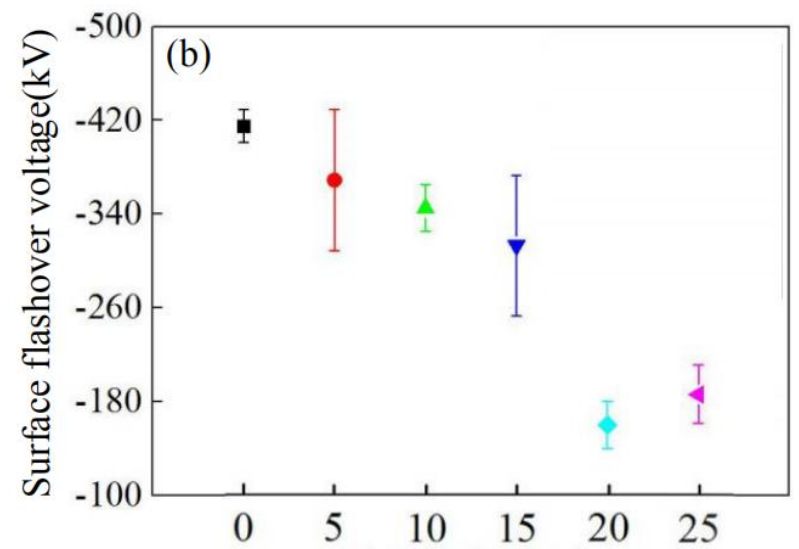

Filler content

Figure 26. DC surface flashover voltage values of insulators with different mass fraction of SiC particles. (a) cone type insulator model and (b) post type insulator model [66]. 
Surprisingly, an opposite trend was reported regarding insulators doped with $\mathrm{SiC}$ [66]. As shown in Figure 26, the DC flashover voltage at $0.4 \mathrm{MPa} \mathrm{SF}_{6}$ gas of cone type insulators and post type insulators with different $\mathrm{SiC}$ contents has descending trend, except for cone type insulator with doping ratios of $20 \%$ and $25 \%$.

\subsubsection{Surface coating}

$\mathrm{ZnO}$ is deposited on epoxy surface by a magnetron sputtering to prepare functional gradient surface layer [64] and the surface flashover voltage was improved significantly. Subsequently, the concept of the interfacial electric field self-regulating (IER) insulator was put forward and the tapered insulator with $\mathrm{EP} / \mathrm{SiC}$ composite material was prepared as the IER insulator [67]. $\beta$-SiC ring-clad insulators with different doping contents $(15 \%, 20 \%$, and $25 \%)$ were prepared and DC surface flashover voltage in the medium of $10 \%$ to $90 \% \mathrm{SF}_{6} / \mathrm{N}_{2}$ mixed gas at 0.1MPa was tested. Figure 27(a) shows the DC flashover voltage results. The flashover voltage of $\mathrm{EP} / \mathrm{SiC}$ coated insulator is higher than conventional insulators, and the surface flashover voltage increases with the increase of SiC content. However, for $\mathrm{EP} / \mathrm{SiC}$-coated insulators with higher $\mathrm{SiC}$ content, the reduced volume resistivity of the $\mathrm{EP} / \mathrm{SiC}$ coating results in higher leakage current and power loss (as shown in Figure 27(b)).

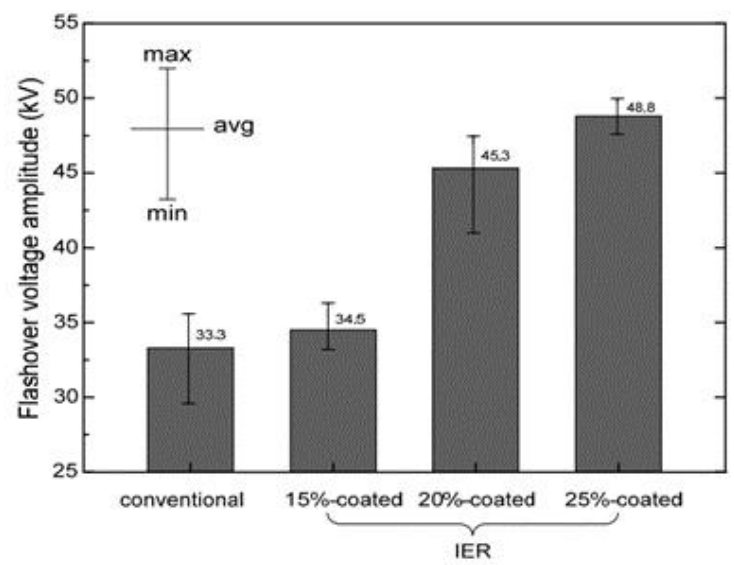

(a)

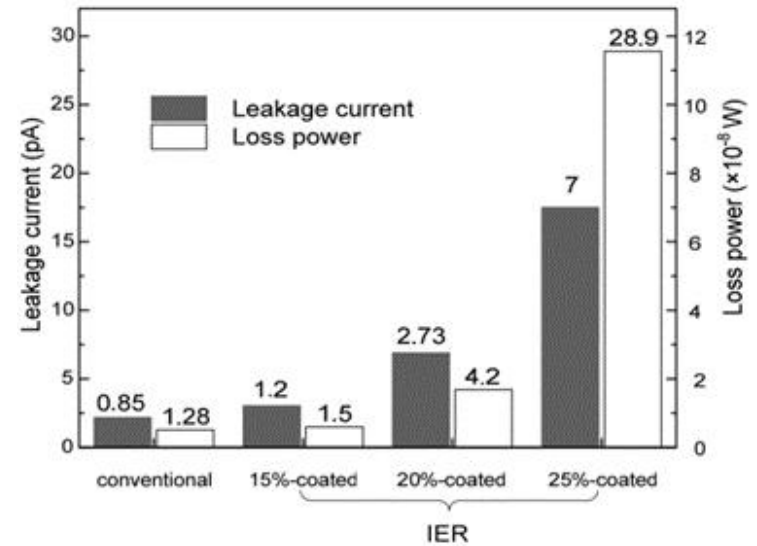

(b)

Figure 27. (a) Measured flashover voltages of the conventional insulator and IER insulators with different SiC contents and (b) leakage current and loss power of the IER insulators with different filler contents [67].

Apart from that, J. Xue et al. sprayed a non-linear conductive coating composed of SiC filler and epoxy on the insulator surface $[68,69]$. The surface charge distribution patterns under DC voltages with different $\mathrm{SiC}$ contents are displayed in Figure 28 [68]. With the increase of $\mathrm{SiC}$ content, surface charges show firstly an increasing and then a decreasing trend. 


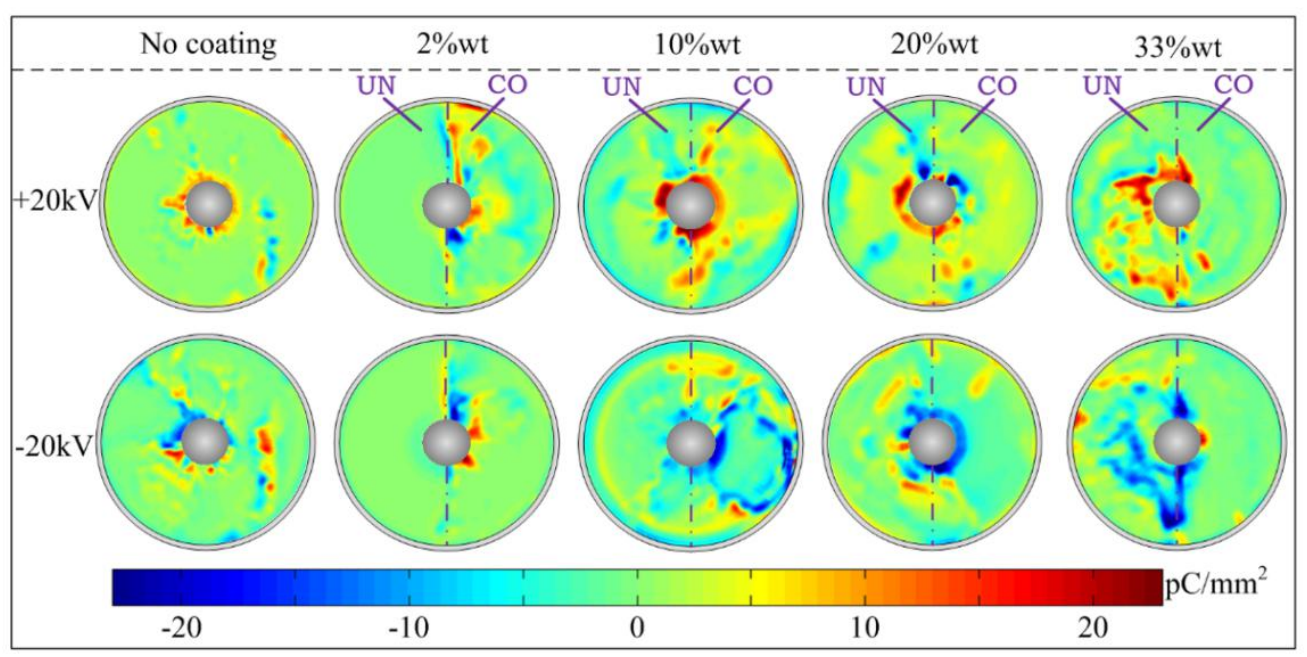

Figure 28. Surface charge distribution patterns with different SiC contents [68].

As an example for the positive flashover test in air at $0.1 \mathrm{MPa}$, the positive flashover voltage is non-linearly distributed by increasing the $\mathrm{SiC}$ content. They divided this phenomenon into three stages: the decline stage $(0-10 \% \mathrm{wt})$, the improvement stage $(10 \% \mathrm{wt}-33 \% \mathrm{wt})$, and the degradation stage $(33 \% \mathrm{wt}$ $-50 \% \mathrm{wt}$ ), as shown in Figure 29 . When the content is $33 \% \mathrm{wt}$, the flashover voltage shows the highest value.

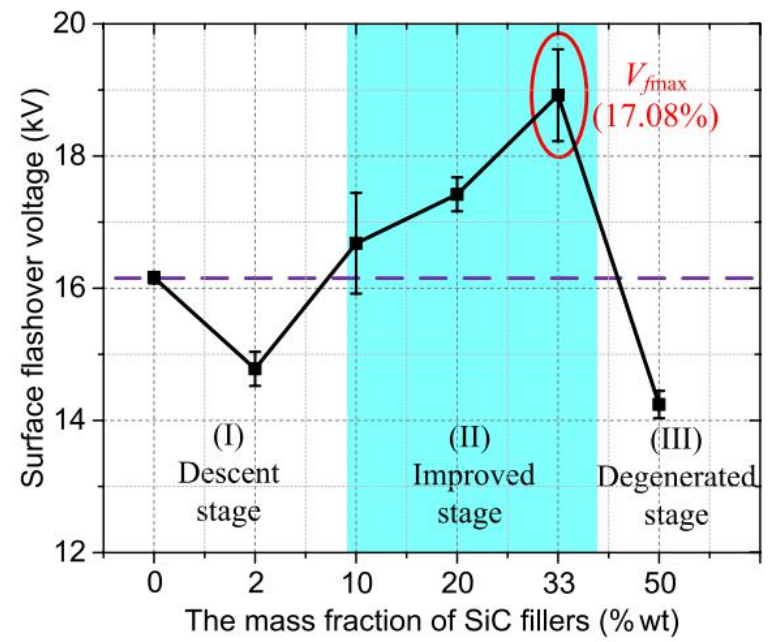

Figure 29. Surface flashover in $0.1 \mathrm{MPa}$ air on $\mathrm{SiC} /$ epoxy coated spacers with different SiC mass fractions [69].

Then J. Xue et al. turned their attention to the influence of SiC particle size in SiC/epoxy coating [70]. As shown in Figure 30, the results showed that surface charges are significantly suppressed by SiC/epoxy coatings, especially using smaller $\mathrm{SiC}$ particle size. Flashover voltage in $0.1 \mathrm{MPa} 20 \% \quad \mathrm{SF}_{6} / \mathrm{N}_{2}$ mixtures increases gradually with decrease of $\mathrm{SiC}$ particle size. 


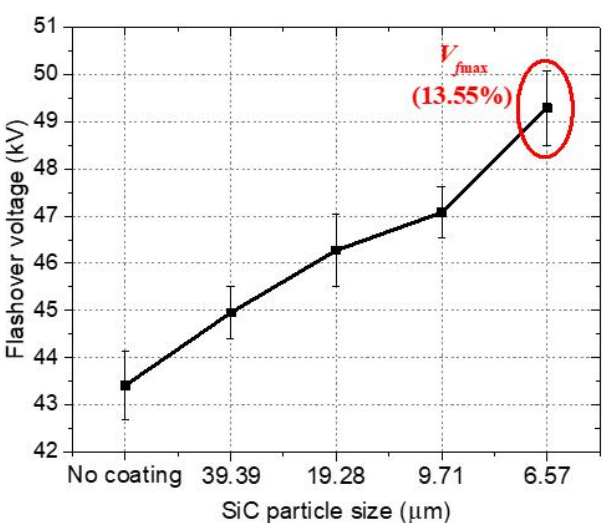

(a)

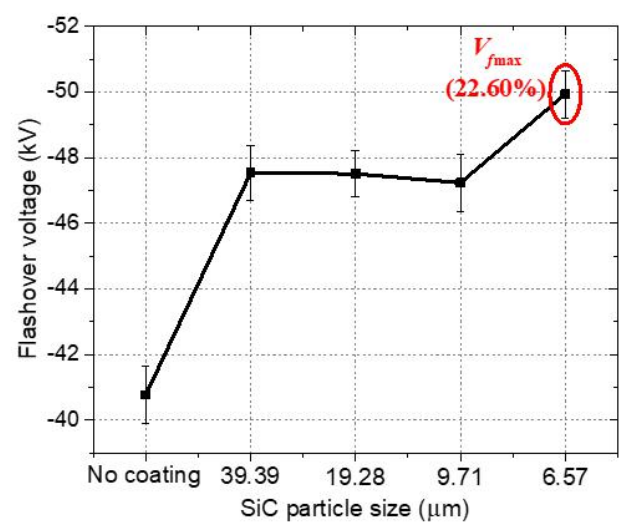

(b)

Figure 30. Flashover voltage of SiC/epoxy coated alumina/epoxy spacers with different $\mathrm{SiC}$ particle size in $0.1 \mathrm{MPa} 20 \% \mathrm{SF}_{6} / \mathrm{N}_{2}$ mixtures. (a) Positive DC. (b) Negative DC [70].

Then they proposed surface conductivity graded coating scheme to overcome the drawbacks of entire coating manner [9]. Four kinds of surface graded coating schemes are considered, as shown in Figure 31.

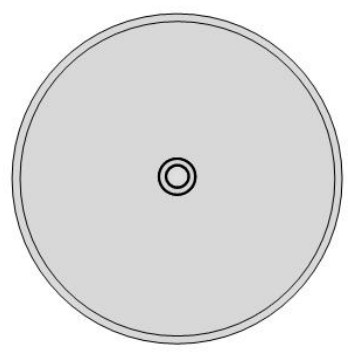

(a)

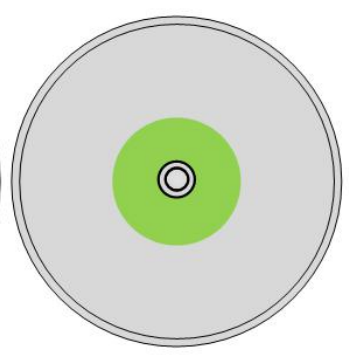

(b)

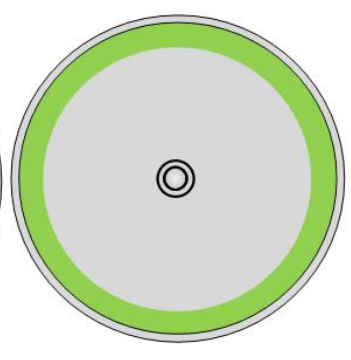

(c)

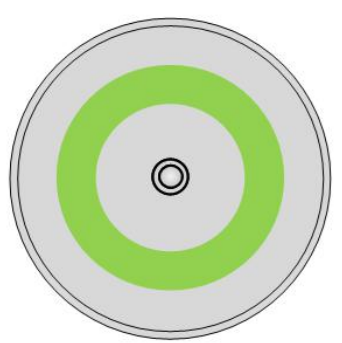

(d)

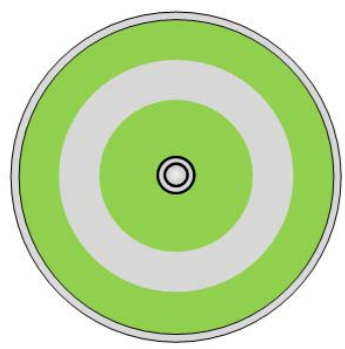

(e)

Figure 31. Different surface graded coating schemes. (a) Raw spacer. (b) High conductive coating locates close to HV electrode (HV-coating). (c) High conductive coating locates close to GND electrode (GND-coating). (d) High conductive coating locates at the middle of spacer surface (SPM-coating). (e) High conductive coating locates close to both HV and GND electrode (HV-GND-coating) [9].

The surface flashover tests are conducted on raw alumina/spacers and with different surface conductivity graded coating (SCGC) schemes when SiC content is $10 \%$ wt. The results are shown in Figure 32. The result shows that HV-coating has the best effect in increasing of surface flashover voltage. 


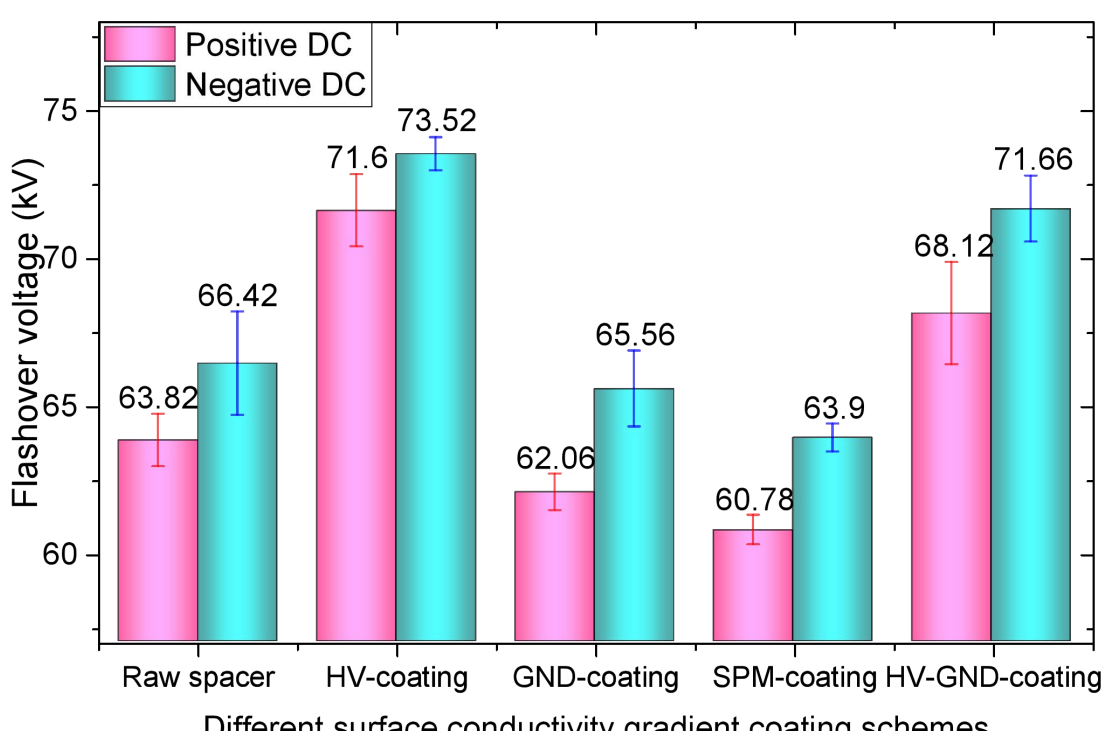

Figure 32. Surface flashover voltage with different SCGC schemes [9].

J. Tang et al. prepared epoxy matrix composites with different contents of nano-SiC particles to coat on epoxy resin [71].Figure 33 shows the surface trap distribution of samples with and without additive of nano-particles. With the $\mathrm{SiC}$ particles doping, shallow traps were introduced, leading to an evidently decline of trap energy level, which would be beneficial to the process of charge de-trapping and extraction.

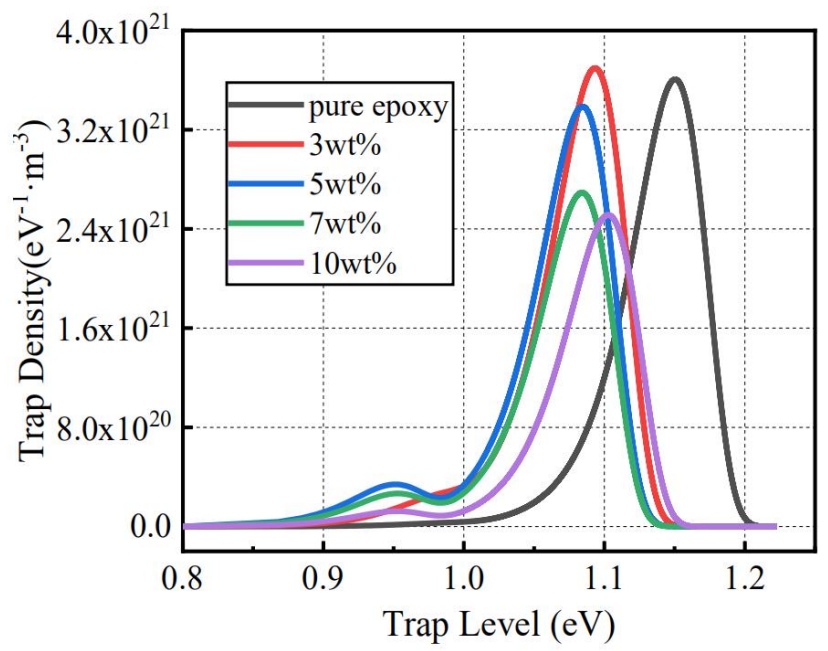

Figure 33. Surface trap distribution of nano-SiC/Epoxy composites [71].

\subsubsection{Analysis and discussion}

In this section we chose representative results from the above mentioned research groups for comparison and discussion. Table 7 summarizes the effect of non-linear conductive composite modifications on the surface potential decay rate and flashover voltage based on the available literature. As it can be seen, a wide 
range of parameters including shape of sample, processing method, test environment, doping amount and applied voltage could directly influence on the results. In literature [63], a direct relationship between doping amount and surface potential decay rate which shows increase of the doping rate for square sheet sample and under positive applied voltage leads to surface potential decay rate enhancement was presented, however, this relation for disc sheet samples and under negative voltage can not be seen. Literature [65] shows that temperature rise increases the rate of surface potential decay for the same doping amount except for $14 \%$ doping at $70{ }^{\circ} \mathrm{C}$. Moreover, the presented results in [67] describes the flashover voltage enhancement with the growth of doping amount for conventional insulator. Zhang et al. investigated the doping amount from 0 to $50 \%$ for cone type spacer and coating processing and the results show the maximum flashover voltage happens at $10 \%$ doping. Literature [66] studied the flashover voltage for different doping amount from 0 to $30 \%$ for two types of samples including post type and cone type insulator; for post type insulators, doping decreases the flashover voltage, yet $25 \%$ doping causes $4.6 \%$ growth of the flashover voltage for cone type insulator.

Meanwhile, regarding the surface flashover voltage at different temperatures, the temperature dependent conductivity should be very important since it affects the charge decay rate significantly, resulting in a changing the surface flashover dispersion. However, problems lie in the difficulty of measuring the surface conductivity at high field and high temperatures since surface flashover would be triggered even at very low field (i.e. $30 \mathrm{kV} / \mathrm{mm}$ ), during surface conductivity measurement, even for well protected and polished electrodes. Meanwhile, in consideration of practical applications, most studies conducted tests at low pressure, which the electric field cannot reach that high compared with the real cases where the gas pressure reaches $0.4 \mathrm{MPa}$ or more. For non-linear materials, due to its property sensitivity with respects to electric field variations, testing under operating conditions must be considered. In addition, the long term aging test and material property variation under transient pulses should further be performed. 
Table 7. Non-linear conductive composite modification methods and corresponding results of each research group.

\begin{tabular}{|c|c|c|c|c|c|c|c|c|c|c|}
\hline \multirow[b]{3}{*}{$\begin{array}{l}\text { Research } \\
\text { group }\end{array}$} & \multirow[b]{3}{*}{ Ref. } & \multirow[b]{3}{*}{$\begin{array}{l}\text { Sample } \\
\text { shape }\end{array}$} & \multirow[b]{3}{*}{$\begin{array}{l}\text { Treatment } \\
\text { method }\end{array}$} & \multirow{2}{*}{\multicolumn{2}{|c|}{ Test environment }} & \multirow{3}{*}{$\begin{array}{l}\text { Doping } \\
\text { mass } \\
\text { ratio }\end{array}$} & \multicolumn{4}{|c|}{ Results } \\
\hline & & & & & & & \multicolumn{2}{|c|}{$\begin{array}{c}\text { Surface potential } \\
\text { measurement }\end{array}$} & \multicolumn{2}{|c|}{ Flashover voltage test } \\
\hline & & & & $\begin{array}{c}\text { Temperature } \\
{ }^{\circ} \mathrm{C}\end{array}$ & $\begin{array}{r}\text { Relative } \\
\text { humidity }\end{array}$ & & $\begin{array}{c}\text { Applied } \\
\text { voltage } \\
\text { kV }\end{array}$ & $\begin{array}{c}\text { Surface } \\
\text { potential } \\
\text { decay ratio at } \\
1200 \mathrm{~s}\end{array}$ & $\begin{array}{c}\text { Environ- } \\
\text { ment }\end{array}$ & $\begin{array}{c}\text { Flashover } \\
\text { voltage } \\
\mathbf{k V} \\
\text { (Increasing } \\
\text { rate) } \\
\end{array}$ \\
\hline \multirow{17}{*}{ B. $\mathrm{Du}$} & \multirow{4}{*}[63]{} & \multirow{4}{*}{ Square sheet } & \multirow{13}{*}{ Doping } & \multirow{4}{*}{20} & \multirow{13}{*}{$30 \%$} & 0 & \multirow{4}{*}{+8} & $5 \%$ & \multirow{13}{*}{ Air $0.1 \mathrm{MPa}$} & \multirow[t]{4}{*}{ 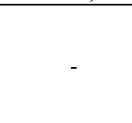 } \\
\hline & & & & & & $3 \%$ & & $7.5 \%$ & & \\
\hline & & & & & & $10 \%$ & & $31.5 \%$ & & \\
\hline & & & & & & $14 \%$ & & $38.1 \%$ & & \\
\hline & \multirow{9}{*}[65]{} & \multirow{9}{*}{ Disc sheet } & & \multirow{3}{*}{20} & & 0 & \multirow{9}{*}{-7} & $19.51 \%$ & & $14.9(0)$ \\
\hline & & & & & & $6 \%$ & & $15.8 \%$ & & $\begin{array}{c}15.6 \\
(+4.8 \%)\end{array}$ \\
\hline & & & & & & $14 \%$ & & $51.9 \%$ & & $\begin{array}{c}17.2 \\
(+15.7 \%)\end{array}$ \\
\hline & & & & \multirow{6}{*}{70} & & 0 & & $84.37 \%$ & & $16.0(0)$ \\
\hline & & & & & & $6 \%$ & & $29.73 \%$ & & $15.2(-5.1 \%)$ \\
\hline & & & & & & $14 \%$ & & $91.3 \%$ & & $\begin{array}{c}14.1 \\
(-12.0 \%)\end{array}$ \\
\hline & & & & & & 0 & & $100 \%$ & & $15.0(0)$ \\
\hline & & & & & & $6 \%$ & & $81.48 \%$ & & $14.3(-5.0 \%)$ \\
\hline & & & & & & $14 \%$ & & $60.78 \%$ & & $\begin{array}{c}12.4 \\
(-17.3 \%)\end{array}$ \\
\hline & \multirow{4}{*}[67]{} & & & & & 0 & & & & $33.3(0)$ \\
\hline & & Conventional & Coating & 25 & - & $15 \%$ & & & $10 \% \mathrm{SF}_{6} / \mathrm{N}_{2}$ & $34.5(+3.6 \%)$ \\
\hline & & insulator & Coatung & 25 & - & $20 \%$ & & & $0.1 \mathrm{MPa}$ & $45.3(+36 \%)$ \\
\hline & & & & & & $25 \%$ & & & & $48.8(+46.5 \%)$ \\
\hline & & & & & & 0 & & & & $-45.0(0)$ \\
\hline & & & & & & $2 \%$ & & & & $-40.0(-11.1 \%)$ \\
\hline G. 7 hang & {$[69]$} & Cone type & Coating & $10-15$ & $<10^{\circ}$ & $10 \%$ & & & $20 \% \mathrm{SF}_{6} / \mathrm{N}_{2}$ & $-54.0(+20 \%)$ \\
\hline U. Znang & {$[09]$} & spacer & Coatung & $10-15$ & $<10 \%$ & $20 \%$ & & & $0.1 \mathrm{MPa}$ & $-53.0(+17.8 \%)$ \\
\hline & & & & & & $33 \%$ & & & & $-34.0(-24.4 \%)$ \\
\hline & & & & & & $50 \%$ & & & & $-30.0(-33.3 \%)$ \\
\hline & & & & & & 0 & & & & $-420(0)$ \\
\hline & & & & & & $5 \%$ & & - & & $-360(-14.3 \%)$ \\
\hline & {$[66]$} & Post type & & & & $10 \%$ & & & $\mathrm{SF}_{6}$ & $-340(-19.0 \%)$ \\
\hline & & insulator & & & & $15 \%$ & & & $0.4 \mathrm{MPa}$ & $-320(-23.8 \%)$ \\
\hline & & & & & & $20 \%$ & & & & $-160(-62.0 \%)$ \\
\hline S. He & & & & & & $25 \%$ & & & & $-180(-57.1 \%)$ \\
\hline S. $\mathrm{He}$ & & & Doping & - & & 0 & & & & $-280(0)$ \\
\hline & & & & & & $5 \%$ & & & & $-245(-12.5 \%)$ \\
\hline & & & & & & $10 \%$ & & & & $-243(-13.2 \%)$ \\
\hline & {$[66]$} & Cone type & & & & $15 \%$ & & & $\mathrm{SF}_{6}$ & $-270(-3.6 \%)$ \\
\hline & & & & & & $20 \%$ & & & & $-290(+3.6 \%)$ \\
\hline & & & & & & $25 \%$ & & & & $-293(+4.6 \%)$ \\
\hline & & & & & & $30 \%$ & & & & $-280(+0 \%)$ \\
\hline
\end{tabular}

\subsection{Shape improvement}

Apart from introducing nonlinear materials which modifies local electric field decently, modifying the profile of insulator to adjust the electric field line distributions can also be a useful approach to suppress charge accumulation and realize local field improvement. In 1982, Cooke found that the charging of the insulator would be associated with a particular nearby source [2], and he believed that the overall geometry of insulators plays an important role in surface charging. Similar conclusions were also presented in his early 
papers [57, 95]. Since Cooke's 1982 paper, the surface charge accumulation phenomenon has been highlighted by researchers using different model spacers.

\subsubsection{Literature review}

In 1983, a very detailed study on surface charging phenomenon and mechanism was conducted by Nakanishi et al. [58]. Based on their experimental results [2, 58], Fujinami put forward an anti-charging spacer model that has no normal field component over the surface, as shown in Figure 34 [56].

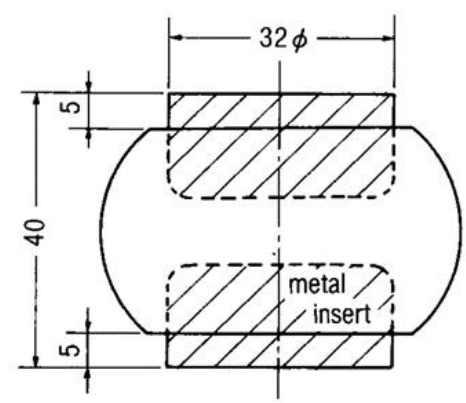

Figure 34. Spacer model designed by Fujinami [56].

After 1988, the investigation of surface charge transport in real-sized spacers accelerates the research progress in exploring the surface charge transport mechanism [54, 55]. However, the implementation of industrial application of HVDC spacers has still been hampered by the non-reproducibility of some experimental results and difficulties in interpreting the surface charge distribution of field measurements. In 1991, Nitta and Nakanishi introduced a design principle that states that the surface of the spacer should intersect the electric field lines at an angle as acute as possible so as to reduce the normal electric field component as much as possible [55]. Based on their design idea, cone type spacer and post type spacer for $\pm 500 \mathrm{kV}$ GIS were manufactured, as shown in Figure 35 . 


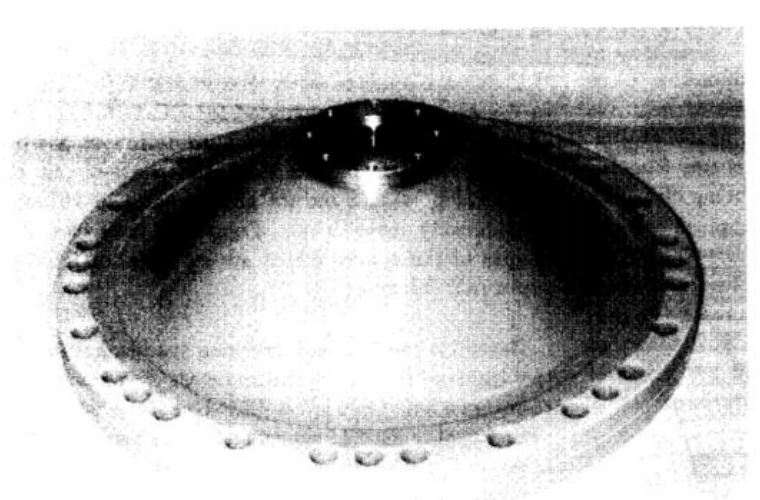

(a)

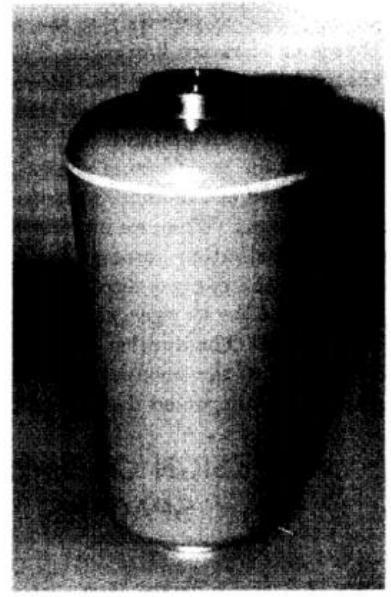

(b)

Figure 35. Spacer for $\pm 500 \mathrm{kV}$ HVDC GIS. (a) Cone type spacer and (b) post type spacer [55].
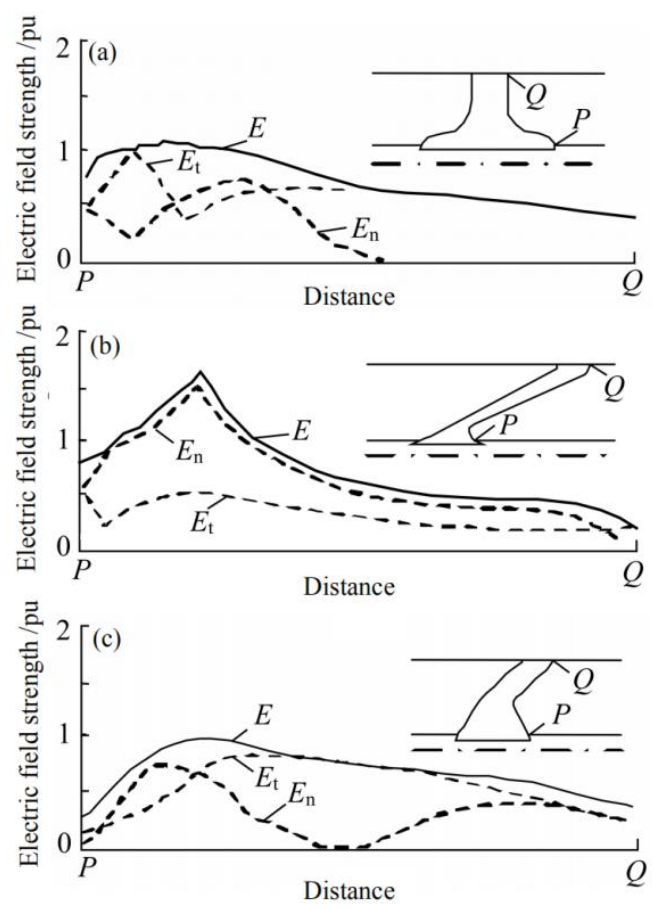

Figure 36. Distributions of electric field and its components on spacer surface concave side. (a) Disc-basin spacer, (b) cone -basin spacer, and (c) half conical-basin spacer [59].

Figure 36 shows the combined field strength $E$, field strength tangential component $E t$ and field strength normal component En calculated by T. Hasegawa et al. for the design of a $500 \mathrm{kV}$ DC GIS bus in 1997 [59]. It can be found that the En of the semi-conical basin insulator is lower than that of the conical insulator, which can effectively suppress the accumulation of surface charges.

In 2004, E. Volpov summarized the general criteria for reliable insulator performance in high-voltage DC gas insulation systems [60], and proposed generalized design criteria for HVDC insulators. He believed that 
the first principle for the optimal design of columnar insulation structures is that the maximum value of the electric field strength along the insulator is smaller than the insulation margin. In this basic principle, the initial normal electric field strength on the gas side of the solid-gas surface should be as small as possible. Meanwhile, for the cone type insulator, the maximum value of the initial normal electric field strength and the initial tangential electric field strength distinctively should be less than the threshold. His research results provide quantifiable design criteria for insulator design applied in HVDC GIS.

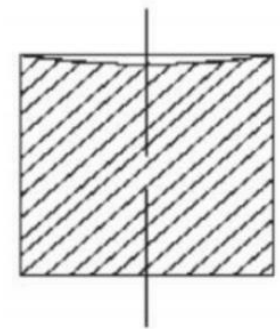

Column

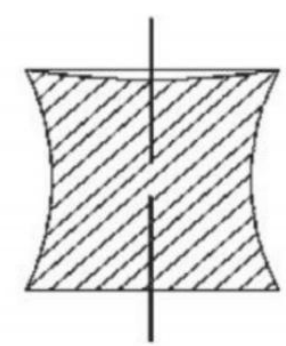

Concave

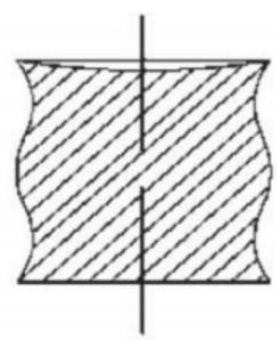

Umbrella skirt

Figure 37. Three different shapes of insulators [62].

Z. Jia et al. focused on the comprehensive influence of the material and shape of the insulator on its flashover characteristics under DC voltage. Figure 37 shows insulators with different shapes used for experimental comparison [62]. The result showed that the flashover voltage of the umbrella skirt insulator was the highest at each pressure.

In our recent research [61], a criterion was put forwordwhich focused on the balance of tangential and normal electric field compments along the surface of insulators. And a novel HVDC cone-type insulator was developed, as shown in Figure 38.

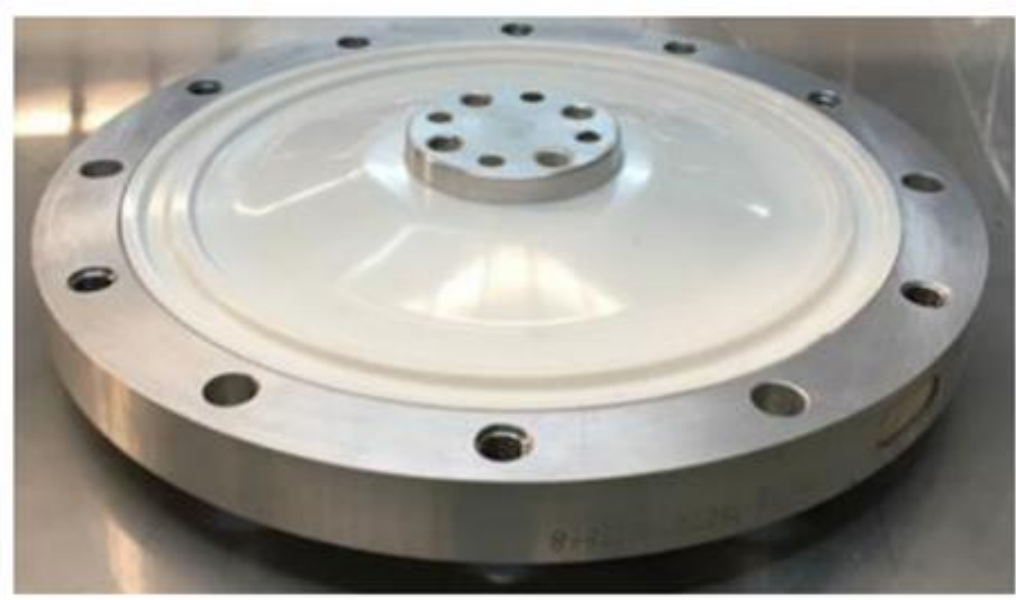

Figure 38. $\pm 100 \mathrm{kV}$ novel DC cone-type insulator [61]. 
The novel DC cone-type insulator passed a series of tests according to standards in gas-insulated equipment [61], which provided a better performance than the traditional AC insulators in the same voltage level. It is noted the flashover voltage of the novel insulator under DC superimposedlightning inpluse voltage, exceeded the evaluation standard. in the $1: 4 \mathrm{SF}_{6} / \mathrm{N}_{2}$ gas mixture at $0.7 \mathrm{Mpa}$.

Meanwhile, a $\pm 200 \mathrm{kV}$ spacer as shown in Figure 39, was further developed. Comparison between the $200 \mathrm{kV}$ dc spacer and a $220 \mathrm{kV}$ AC spacer was performed by DC surface flashover and polarity reversal tests at $0.3 \mathrm{MPa} \mathrm{SF}_{6}$ (as shown in Figure 40). For DC spacer, the surface charge density of convex surface is lower than $10 \mu \mathrm{C} / \mathrm{m}^{2}$, and that of concave surface is lower than $5 \mu \mathrm{C} / \mathrm{m}^{2}$. For AC spacer, the surface charge density of concave surface is higher than $10 \mu \mathrm{C} / \mathrm{m}^{2}$, and it even reaches to $18 \mu \mathrm{C} / \mathrm{m}^{2}$ on the convex surface. The flashover voltage of AC and DC spacers are both lower than that in the DC linear-boost test. The flashover voltage of AC spacer after polarity reversal decreases more than that of DC spacer, from $420 \mathrm{kV} \sim 440 \mathrm{kV}$ to less than $360 \mathrm{kV}$. In addition, the linear-boost flashover voltage of DC spacer is slightly higher and more stable than the AC spacer. The polarity reversal flashover voltage of DC spacer is slightly lower than the linear-boost flashover voltage.
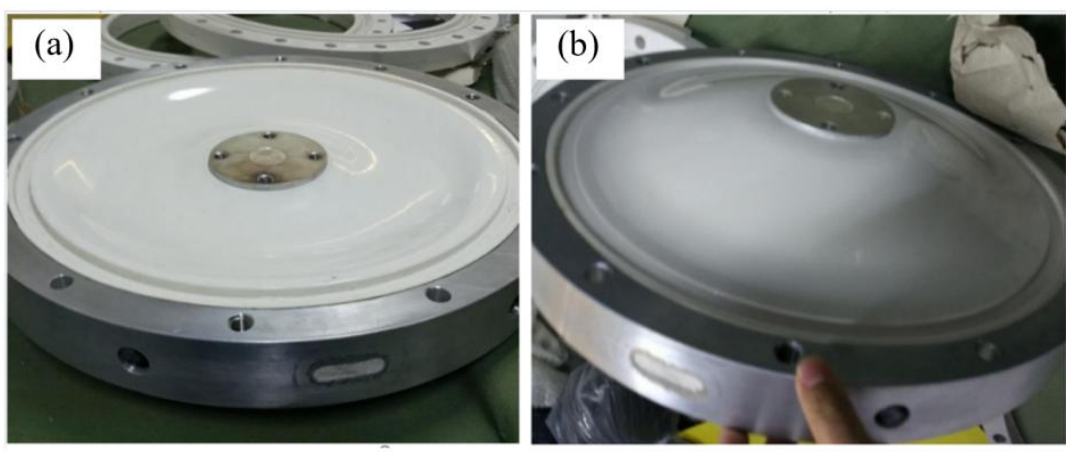

Figure 39. Physical pictures of the DC spacer. (a) Concave surface side and (b) convex surface side.

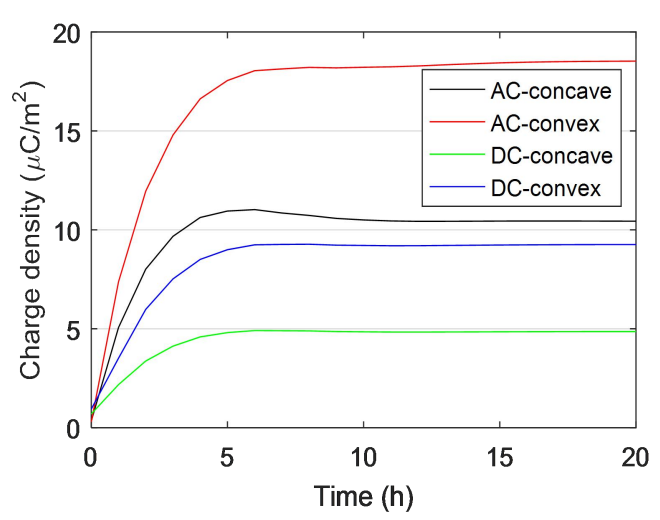

(a)

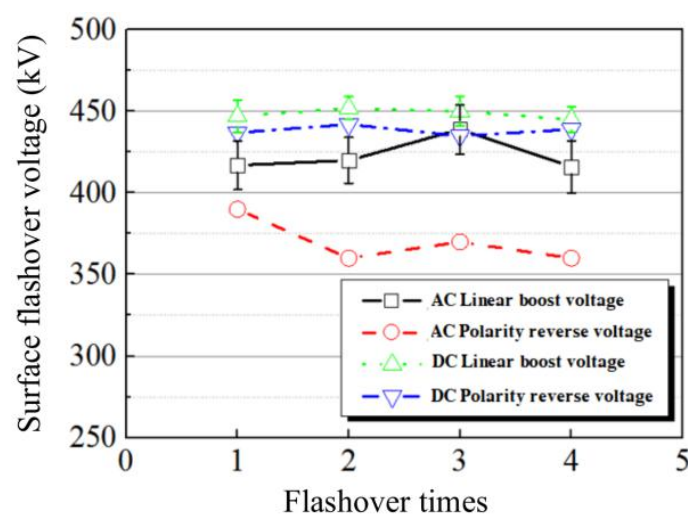

(b) 
Figure 40. (a) Time varying curves of surface charge density along the surface of AC and DC spacers after applying $240 \mathrm{kV}$ voltage, and (b) surface flashover voltage test results at $0.3 \mathrm{MPa} \mathrm{SF} 6$.

One difficulty with gas-insulated components under DC stress is to predict the field distribution in the solid spacers and in the gas in the vicinity of the spacers. DC spacers must be able to withstand not only long time DC stress but also switching and lightning overvoltages and DC polarity reversal. All these factors have to be considered when DC spacers are designed. There is therefore a need to develop methods to investigate charge accumulation and field distributions on spacer surfaces. As a charging counter measure surface coating of insulators was introduced for the first time. The spacers used were made of a standard epoxy with alumina filler. Some of the spacers have been covered with a slightly conducting film. The spacer surfaces were cleaned with alcohol before mounting. This treatment gave charge-free surfaces. The potential shift for the covered spacers reached its equilibrium faster in a few days. After polarity reversal, the potential shift reversed and reached steady state with the same time constant as before. In Figure 41 a summary of obtained results for both coated and uncoated spacers is shown. The faster re-distribution on the coated spacers documents that in this case surface conduction is the dominant process. As a summary the results from the 1980s obtained for uncoated and coated surfaces indicate that suitably chosen surface coatings can be used to control the field distribution at the surface of solid spacers under HVDC stress, making $\mathrm{SF}_{6}$ insulated components feasible in HVDC applications as well as in HVAC.

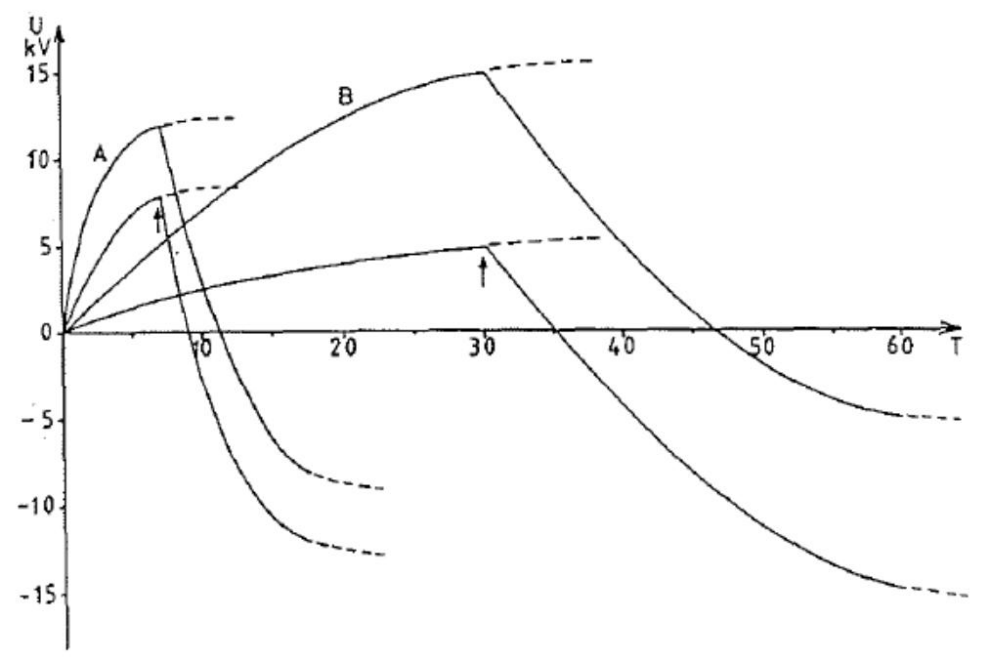

Figure 41. The time dependence of max and min voltages of the initial zero contour for the coated (A) and uncoated spacer (B). The time (T) is given in days. The arrows indicate polarity reversals [12]. 
Another approach to avoid charge accumulation is to make the resistive field distribution equal or similar to the capactive field distribution by design and proper choice of material properties[56, 96-98]. The influence of temperature and temperature distribution must be considered.

The magnitude of the electric field at the solid-gas insulation interface (gas side) for various ion densities is shown in Figure 42. For short times, the capacitive field (denoted AC) is tangential to the surface, resulting in a negligible ion capture volume and a maximum field located near the HV conductor. In contrast, for the DC steady state (no ion case), the presence of a temperature gradient across the insulation enhances the field in the less conductive region, i.e. near the grounded tank. For the same reason, DC field lines in the gas toward the solid have now a normal component and build up a capture volume for ions[99].

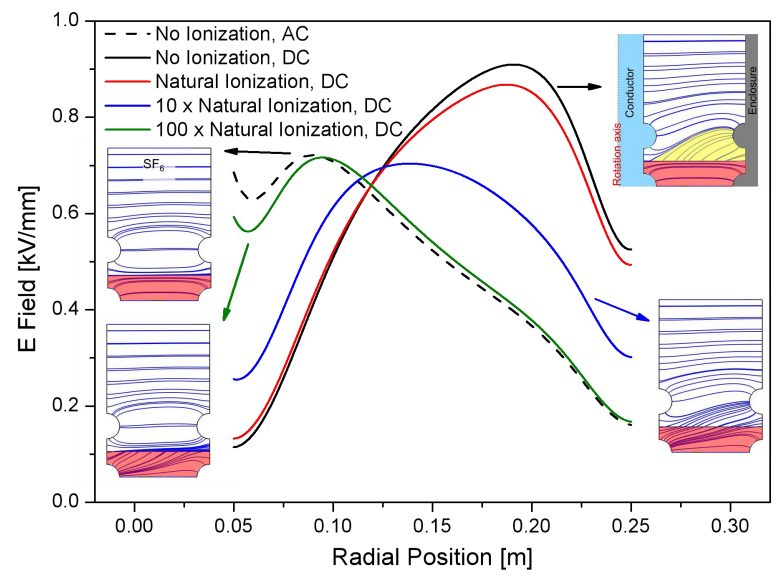

Figure 42. Electrical field at the solid-gas interface for various ion production rates. Insets show field lines in the gas (white) and solid (red) with example of ion capture volume (yellow region) [99].

Based on the research for material characterisation and the usage of multi-physics simulation tools the analysis of electrical field distribution is now possible with high precision, taking the following parameters into consideration: temperature and electrical field dependent characteristics of the used insulating materials, accumulation of space- and surface charges and the superposition of DC and impulse voltages[100]. Hence, the comparison between capacitive and steady-state resistive electric field strength distribution (gas side) for the HVAC partition insulator (Figure 43) and the new developed HVDC partition insulator (Figure 43), shows lower dielectric stress on the DC-design and under DC with some minor drawback in the case of AC[101]. 


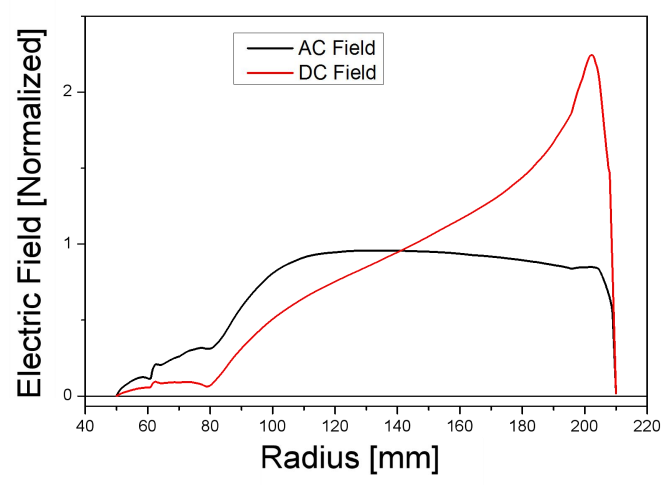

Figure 43. Comparison between capacitive and steady-state resistive electric field strength distribution (gas side) for the HVAC partition [101].

For the optimized HVDC design, the improvement shown with a significant reduction of the dielectric stress was obtained by geometrical optimization and insertion of a current collector, compared to the AC design[102]. The temperature gradient across the insulation considered for the simulation is equal to the worst case under service conditions and maximum continuous current.

\subsubsection{Analysis and discussion}

Shape modification as an approach to suppress surface charge accumulation of the insulator has advantages such as simple operation process and high reliability, which is preferred by manufactures. The temperature dependent conductivity may influence electric field distributions at DC, which results in irregular charge behaviors. This issue should be considered carefully. Currently, we see some favorable evidences regarding manufacturing of HVDC spacers, as is discussed in $[61,101,102]$, however, it is still a pity that no design margin used for qualifying a charge density as well as a electric field stress/normal component value that is acceptable for the stable operation of HVDC spacers. This unfavorable situation is mainly due to the lack of knowledge regarding mechanism of charge triggered surface flashover at DC voltage. Some footprints explaining charge-induced flashover are discussed in [14] and [17]. However, there is a long road ahead for us before filling this research gap.

\section{Comprehensive management-initiatively charge decay method}


A novel design of HVDC spacer (shown in Figure 44) was introduced based on the concept of adaptively controlling surface charges using nonlinear materials. This method, unlike commonly used traditional approaches, proposed a novel idea of controlling the location of accumulated charges and then properly decaying of these charges, which fundamentally solves the problem of surface charge accumulation. The electrical and mechanical test results show that the charge adaptively controlled spacer has high operating capability under DC voltage and has great industrial application potential [72-75].

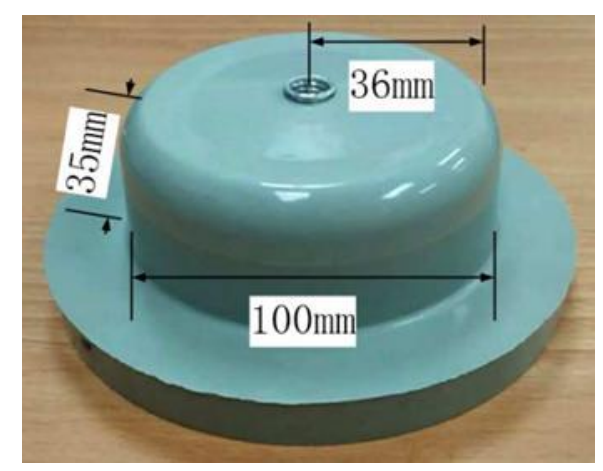

Figure 44. Side view of the charge adaptively controlling spacer [73].

The charge adaptively controlled spacer with a mass ratio of $20 \% \mathrm{SiC}$ in the insulation region and $30 \%$ $\mathrm{SiC}$ in the charge adaptively controlled region shows the best results as indicated in Figure 45 [75].

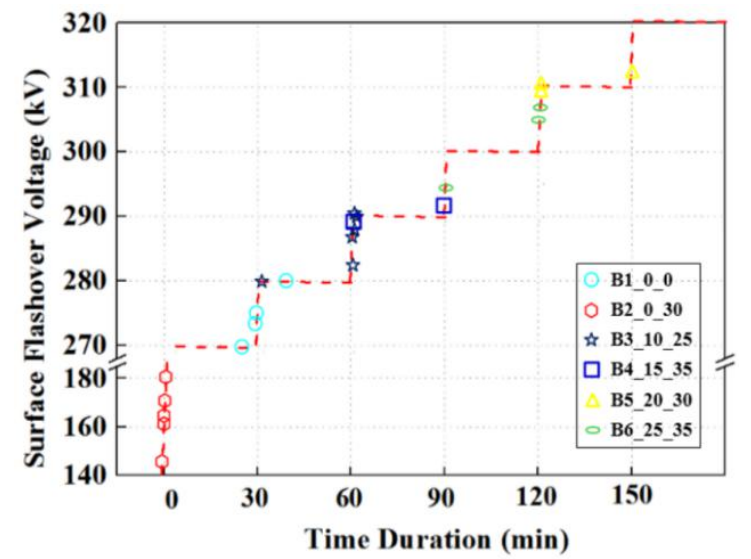

Figure 45. DC surface flashover test results of experimental samples (red line shows the increasing of dc voltage ) [75].

\section{Challenges and suggestions for future work}

7.1 Surface charge origin and models 
Before choosing the charge tailoring methods, we should firstly clarify the charge type we were to deal with, i.e. the homo-polarity charge due to conduction current and/or the hetero-polarity charge from the gas. Under this premise, we can regulate the charge in a targeted manner. Recently published research proposes a fairly convincing field-dependent charging theory, as has already discussed in the introduction, which can serve as a reference for ways determining charge origins [16].

Based on the charge origins, this paper introduces a Dam-flood model and classifies the surface charge tailoring methods proposed by different researchers. However, during chemically changing the surface conductivity, which has been verified to be an important way changing surface flashover voltage, the surface morphology is usually changed. This makes it difficult for us to discern what parameter plays a decisive role in surface flashover voltage improvement. For example, in the fluorination process, is it the morphology optimization or the increase of conductivity that really contributes to the surface flashover improvement? Further, surface conductivity determines surface charge dissipation performance, which is an important parameter that has been evaluated in the scheme by researchers. However, results obtained by previous researchers showed different conductivity values that make it impossible to compare and find the optimal margin to determine a suitable surface conductivity suitable for industry application.

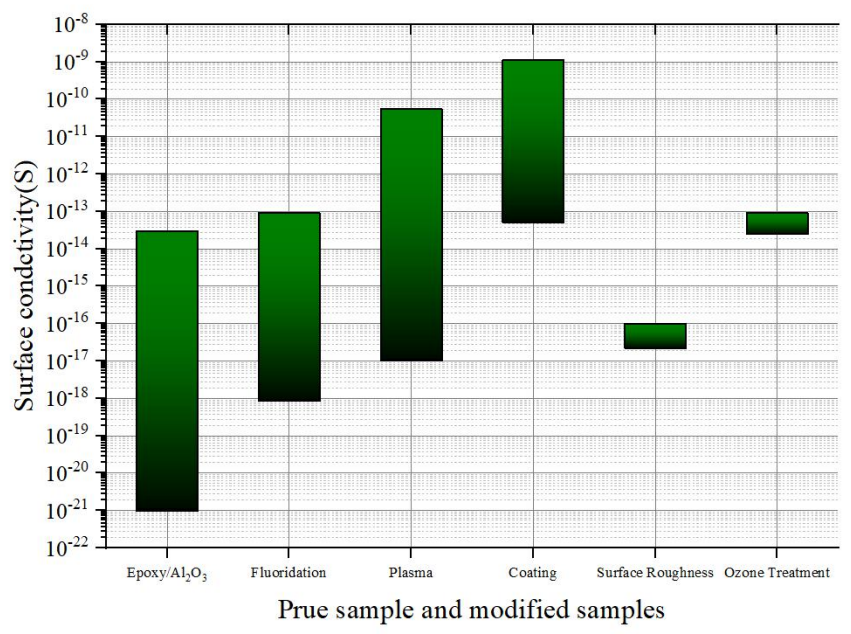

Figure 46. Distribution range of the surface conductivity of epoxy based samples before and after surface modification.

Figure 46 presents the surface conductivity of epoxy based samples before and after surface modification.[24, 31, 32, 41, 42, 44, 49, 85, 90] It is worth noting that the surface conductivity of the base material without modification defers significantly, which ranges from $9.7 \times 10^{-22} \mathrm{~S}$ to $3.4 \times 10^{-14} \mathrm{~S}$. Surface 
modification increases surface conductivity and better surface property can be obtained. Further, we can see that fluorination results in a surface conductivity ranging from $8.6 \times 10^{-19} \mathrm{~S}$ to $9 \times 10^{-14} \mathrm{~S}$, which is relative lower compared with plasma treatment. However, coatings introduce a surface conductivity up to $1.11 \times 10^{-9} \mathrm{~S}$ which is much higher compared with other surface modification methods. Surface roughness and ozone treatment increase surface flashover voltage while the trivial surface conductivity change is shown.

Such large difference over results in surface conductivity, to our knowledge, can be partially due to differences in test setup and environment condition (i.e., air pressures, ambient gases), electrode arrangement, electric fields, etc.. Meanwhile, as a variable material which shows different properties produced by different companies, epoxy resin may probably be another factor responsible for such variations in measurement results. We would suggest that all tests and measurements to be based on practical industrial applications, and the test environmental condition should strictly follow the industrial application environment. In addition, there are various methods for characterizing material properties, and there is still a lack of unified measurement standards. Even if the same epoxy resin and the same processing technology are used, the conductivity measured by each research group is different, and some are several orders of magnitude different. (For example, the untreated epoxy conductivity measurement Z. An and G. Chen's group are different [19-21, 27, 28], and after the same treatment method, the surface conductivity of fluorinated samples such as J. He and B. Du have a greater difference [30-32]). Such dispersion makes it difficult to compare and evaluate the effectiveness of a certain treatment method, which hinders the selection of surface conductivity during the preparation of insulators operating under DC voltage. It is necessary that the same measurement methods and conditions are selected to ensure replicability of tests to obtain the similar measured values. We recommend the conductivity measurement guidelines proposed in [103], by E.C. Salthouse. Based on this criterion, extension of measurement time to $24 \mathrm{~h}$ is needed to further ensure the stability and accuracy of the results. The measurement environment is suggested to be combined with the real operating environment of the insulator, especially for the use of non-linear materials as modified insulators.

\subsection{Conductivity and traps}


Regarding the all charge tailoring techniques mentioned in this work, resistivity and traps are parameters that researchers concerned more about. The transition of electrons from the Fermi level to the conduction band requires energy to overcome the forbidden band whose width represents the resistivity of the polymer. When the polymer is modified either by surface modification or the volume doping, it is equivalent to introduce new impurities whose energy levels locates intermittently between the Fermi level and the conduction band of the polymer. Under such case, when the electrons cross the forbidden band, the energy levels introduced by impurities serves as a 'step', and it will be easier for electrons to overcome the forbidden band before reaching the conduction band. As a consequence, it can be conceived that the forbidden band becomes narrower and the trap density of the material becomes shallower, resulting in smaller resistivity [104].

As has been indicated by researchers that shallow traps increase surface charge decay, which is similar to the effect of increasing surface conductivity. Meanwhile, it has been verified that a surface with higher conductivity facilitates surface charge decay in a manner of surface leakage current while surface charge decays through bulk or/and recombination with charges of opposite polar in air when a surface with low conductivity s used [105-107]. It should be emphasized that deep traps can only be effective to inhibition of charge injection as a manner to suppress surface charge accumulation in case they are being created in the electrode/dielectric interface other than over the gas/solid interface-which prevents charge decay from insulator surface.

\section{Conclusion}

This paper introduces a Dam model, based on which surface charge tailoring techniques are classified and reviewed in a manner of increasing surface charge decay, inhibiting homo-polar charges from volume conduction, decaying/avoiding charges at high electric field, and initiatively controlling and decaying charges. Technical solutions of different charge tailoring methods are compared and discussed. The outlook of potential solutions to suppress charge accumulation is recommended and discussed based on industrial consideration. Based on the reviewing of published literature, we can sense that the current researches still needs further improvement, especially in the unity of measurement methods as well as the mechanism of increasing of surface flashover voltage. Meanwhile, for further studies, the transition from laboratory research 
to industrial production should also be considered. Before successfully developing of charge-free insulators, the progress and improvement in this field requires our joint efforts both in charge tailoring mechanism and treatment method.

\section{Acknowledgement}

This work was supported in part by the National Natural Science Foundation of China (Grant No. $51677113)$.

\section{References}

[1] Li C, Lin C, Zhang B, Li Q, Liu W, Hu J and He J 2018 Understanding surface charge accumulation and surface flashover on spacers in compressed gas insulation IEEE Transactions on Dielectrics and Electrical Insulation 25 1152-66

[2] Cooke C M 1982 Charging of Insulator Surfaces by Ionization and Transport in Gases IEEE Transactions on Electrical Insulation EI-17 $172-8$

[3] Zhang L, Lin C, Li C, Suraci S, Chen G, Riechert U, Shahsavarian T, Hikita M, Tu Y, Zhang Z, Fabiani D and He J 2020 Gas-solid interface charge characterization techniques for HVDC GIS/GIL insulators High Voltage

[4] Dey A, De S, De A and De S K 2004 Characterization and dielectric properties of polyaniline- $\mathrm{TiO}_{2}$ nanocomposites Nanotechnology 15 $1277-83$

[5] Pan L K, Sun C Q, Chen T P, Li S, Li C M and Tay B K 2004 Dielectric suppression of nanosolid silicon Nanotechnology 15 1802-6

[6] Tanaka T 2005 Dielectric nanocomposites with insulating properties IEEE Transactions on Dielectrics and Electrical Insulation 12914-28

[7] Wang T, Zhang B, Li D-Y, Hou Y-C and Zhang G-X 2020 Metal nanoparticle-doped epoxy resin to suppress surface charge accumulation on insulators under DC voltage Nanotechnology 31

[8] Wang T-Y, Zhang B-Y, Li D-Y, Hou Y-C and Zhang G-X 2020 A single-electron tunneling model: a theoretical analysis of a metal nanoparticle-doped epoxy resin to suppress surface charge accumulation on insulators subjected to DC voltages Nanotechnology 31475707

[9] Xue J, Chen J-H, Dong J-H, Deng J and Zhang G-J 2020 Enhancing flashover performance of alumina/epoxy spacers by adaptive surface charge regulation using graded conductivity coating Nanotechnology 31364002

[10] Guan H, Chen X, Du H, Jiang T, Paramane A and Zhou H 2020 Surface potential decay and DC surface flashover characteristics of DBD plasma-treated silicone rubber Nanotechnology 31424005

[11] Riechert U, Straumann U and Gremaud R 2016 Compact gas-insulated systems for high voltage direct current transmission: Basic design. In: IEEE PES Transmission \& Distribution Conference \& Exposition (T\&D), (Kay Bailey Hutchison Convention Center Dallas, Texas, USA pp $1-5$

[12] R. Alvinsson, E. Borg, A. Hjortsberg, T. Höglund and Hörnfeldt S 1986 GIS for HVDC Converter Stations. In: CIGRE

[13] Mendik M, Lowder S M and Elliott F 1999 Long term performance verification of high voltage DC GIS. In: IEEE Transmission and Distribution Conference, pp 484-8 vol.2

[14] Li C et al 2020 J. Phys. D: Appl. Phys. https://doi.org/10.1088/1361-6463/abb38f

[15] Li C, Xu Y, Lin C, Chen G, Tu Y, Zhou Y, Lei Z, Han T, Suraci S, Wang J, Liu W, Nazir M T, He S, Cavallini A, Mazzanti G, Fabiani D and He J 2019 Surface Charging Phenomenon on HVDC Spacers in Compressed $\mathrm{SF}_{6}$ Insulation and Charge Tailoring Strategies Journal of Power and Energy Systems 6

[16] Li C, Lin C, Chen G, Tu Y, Zhou Y, Li Q, Zhang B and He J 2019 Field-dependent charging phenomenon of HVDC spacers based on dominant charge behaviors Applied Physics Letters 114 
[17] Li C, Hu J, Lin C and He J 2017 The potentially neglected culprit of DC surface flashover: electron migration under temperature gradients Scientific Reports 7

[18] An Z, Yin Q, Liu Y, Zheng F, Lei Q and Zhang Y 2015 Modulation of Surface Electrical Properties of Epoxy Resin Insulator by Changing Fluorination Temperature and Time IEEE Transactions on Dielectrics and Electrical Insulation 22 526-34

[19] Liu Y, An Z, Cang J, Zhang Y and Zheng F 2012 Significant Suppression of Surface Charge Accumulation on Epoxy Resin by Direct Fluorination IEEE Transactions on Dielectrics and Electrical Insulation 19 1143-50

[20] Liu Y, An Z, Cang J, Zheng F and Zhang Y 2011 Preliminary Study on Surface Properties of Surface Fluorinated Epoxy Resin Insulation. In: IEEE Proceedings of 2011 International Conference on Electrical Insulating Materials pp 109-12

[21] Liu Y, An Z, Yin Q, Zheng F, Lei Q and Zhang Y 2013 Characteristics and Electrical Properties of Epoxy Resin Surface Layers Fluorinated at Different Temperatures IEEE Transactions on Dielectrics and Electrical Insulation 20 1859-68

[22] Liu Y, An Z, Yin Q, Zheng F, Zhang Y and Lei Q 2013 Rapid potential decay on surface fluorinated epoxy resin samples Journal of Applied Physics 113

[23] Que L, An Z, Ma Y, Shan F, Zhang Y, Zheng F and Zhang Y 2018 High Resistance of Surface Fluorinated Epoxy Insulators to Surface Discharge in $\mathrm{SF}_{6}$ Gas IEEE Transactions on Dielectrics and Electrical Insulation 25 245-52

[24] Zhang B, Zhang G, Wang Q, Li C, Jinliang H and An Z 2015 Suppression of surface charge accumulation on $\mathrm{Al}_{2} \mathrm{O}_{3}$-filled epoxy resin insulator under DC voltage by direct fluorination AIP Advances 5127207

[25] Mohamad A, Chen G, Zhang Y and An Z 2015 Surface Fluorinated Epoxy Resin for High Voltage DC Application IEEE Transactions on Dielectrics and Electrical Insulation 22 101-8

[26] Mohamad A, Chen G, Zhang Y and An Z 2016 Moisture Effect on Surface Fluorinated Epoxy Resin for High-voltage DC Applications IEEE Transactions on Dielectrics and Electrical Insulation 23 1148-55

[27] Mohamad A, Chen G, Zhang Y and An Z 2013 Influence of Fluorination Time on Surface Flashover of Polymeric Insulation. In: IEEE Conference on Electrical Insulation and Dielectric Phenomena, pp 482-5

[28] Mohamad A, Chen G, Zhang Y andAn Z 2013 Surface Potential Decay measurements on Fluorinated Polymeric Insulation for High Voltage DC Applications. In: IEEE Conference on Electrical Insulation and Dielectric Phenomena, pp 1132-5

[29] Mohamad A, Chen G, Zhang Y and An Z 2014 Mechanisms for surface potential decay on fluorinated epoxy in high voltage DC applications. In: IEEE Conference on Electrical Insulation and Dielectric Phenomena, pp 863-6

[30] Du B, Du Q, Li J and Liang H 2018 Carrier mobility and trap distribution dependent flashover characteristics of epoxy resin IET Generation Transmission \& Distribution 12 466-71

[31] Du B, Ran Z, Li J and Liang H 2019 Novel Insulator with Interfacial sigma-FGM for DC Compact Gaseous Insulated Pipeline IEEE Transactions on Dielectrics and Electrical Insulation 26 818-25

[32] $\mathrm{Li} \mathrm{C}$, He J and Hu J 2016 Surface Morphology and Electrical Characteristics of Direct Fluorinated Epoxy-resin/Alumina Composite IEEE Transactions on Dielectrics and Electrical Insulation 23 3071-77

[33] Li C, Hu J, Lin C and He J 2016 The control mechanism of surface traps on surface charge behavior in alumina-filled epoxy composites Journal of Physics D-Applied Physics 49

[34] Li C, Hu J, Lin C, Zhang B, Zhang G and He J 2016 Fluorine gas treatment improves surface degradation inhibiting property of alumina-filled epoxy composite Aip Advances 6

[35] Li C, Hu J, Lin C, Zhang B, Zhang G and He J 2017 Surface charge migration and DC surface flashover of surface-modified epoxy-based insulators Journal of Physics D-Applied Physics $\mathbf{5 0}$

[36] Que L, An Z, Ma Y, Xie D, Zheng F and Zhang Y 2017 Improved DC Flashover Performance of Epoxy Insulators in SF 6 Gas by Direct Fluorination IEEE Transactions on Dielectrics and Electrical Insulation 24 1153-61

[37] Shao T, Kong F, Lin H, Ma Y, Xie Q and Zhang C 2018 Correlation between Surface Charge and DC Surface Flashover of Plasma Treated Epoxy Resin IEEE Transactions on Dielectrics and Electrical Insulation 25 1267-74

[38] Shao T, Liu F, Hai B, Ma Y, Wang R and Ren C 2017 Surface Modification of Epoxy Using an Atmospheric Pressure Dielectric Barrier Discharge to Accelerate Surface Charge Dissipation IEEE Transactions on Dielectrics and Electrical Insulation 24 1557-65 
[39] Wang R, Lin H, Gao Y, Ren C, Ostrikov K and Shao T 2017 Inorganic nanofilms for surface charge control on polymer surfaces by atmospheric-pressure plasma deposition Journal of Applied Physics 122233302

[40] Zhang C, Lin H, Zhang S, Xie Q, Ren C and Shao T 2017 Plasma surface treatment to improve surface charge accumulation and dissipation of epoxy resin exposed to DC and nanosecond-pulse voltages Journal of Physics D-Applied Physics $\mathbf{5 0} 405203$

[41] Zhang C, Ma Y, Kong F, Wang R, Ren C and Shao T 2019 Surface Charge Decay of Epoxy Resin Treated by AP-DBD Deposition and Direct Fluorination IEEE Transactions on Dielectrics and Electrical Insulation 26 768-75

[42] Zhang C, Ma Y, Kong F, Yan P, Chang C and Shao T 2019 Atmospheric pressure plasmas and direct fluorination treatment of $\mathrm{Al}_{2} \mathrm{O}_{3}$-filled epoxy resin: A comparison of surface charge dissipation Surface \& Coatings Technology 362 1-11

[43] Hai B, Zhang C, Wang R, Zhang S, Chen G and Shao T 2017 Plasma-deposited $\mathrm{SiO}_{2}$-like thin film suppresses charge accumulation on epoxy resin surface High voltage technology 43 375-84 (in Chinese)

[44] Yue W, Min D, Nie Y and Li S 2018 Plasma treatment enhances surface flashover performance of $\mathrm{EP} / \mathrm{Al}_{2} \mathrm{O}_{3}$ micro-composite in vacuum. In: 2018 12th International Conference on the Properties and Applications of Dielectric Materials (ICPADM), pp 1086-9

[45] Tu Y, Zhou F, Cheng Y, Jiang H, Wang C, Bai F and Lin J 2018 The Control Mechanism of Micron and Nano $\mathrm{SiO}_{2} /$ Epoxy Composite Coating on Surface Charge in Epoxy Resin IEEE Transactions on Dielectrics and Electrical Insulation 25 1275-84

[46] Tu Y, Zhou F, Jiang H, Bai F, Wang C, Lin J and Cheng Y 2018 Effect of Nano-TiO $/$ EP Composite Coating on Dynamic Characteristics of Surface Charge in Epoxy Resin IEEE Transactions on Dielectrics and Electrical Insulation 25 1308-17

[47] Gao Y, Du B , Cui J and Wu K 2011 Effect of Gamma-Ray Irradiation on Lateral Charge Motion on Surface of Laminated Polymer Insulating Materials. In: IEEE Annual Report Conference on Electrical Insulation and Dielectric Phenomena, Vols 1 And 2, pp 153-6

[48] Gao Y, Du B , Ma Z and Zhu X 2010 Decay Behavior of Surface Charge on Gamma-Ray Irradiated Epoxy Resin. In: IEEE Proceedings of the 2010 IEEE International Conference on Solid Dielectrics.

[49] Huang Y, Min D, Xie D, Li S, Wang X and Lin S 2017 Surface Flashover Performance of Epoxy Resin Microcomposites Infulenced by Ozone Treatment. In: 2017 International Symposium on Electrical Insulating Materials

[50] Baytekin H T, Baytekin B, Hermans T M, Kowalczyk B and Grzybowski B A 2013 Control of Surface Charges by Radicals as a Principle of Antistatic Polymers Protecting Electronic Circuitry Science 341 1368-71

[51] $\mathrm{Li} \mathrm{C}, \mathrm{Hu}$ J, Lin C and He J 2016 Hot Electron Injection Regulation in $\mathrm{Al}_{2} \mathrm{O}_{3}$-filled Epoxy Resin Composite Using $\mathrm{Cr}_{2} \mathrm{O}_{3}$ Coatings. In:IEEE Conference on Electrical Insulation and Dielectric Phenomena, pp 101-4

[52] Zhang B, Gao W, Hou Y and Zhang G 2018 Surface Charge Accumulation and Suppression on Fullerene-filled Epoxy-resin Insulator under DC Voltage IEEE Transactions on Dielectrics and Electrical Insulation $252011-9$

[53] $\mathrm{He} \mathrm{S}$, Lin C, Hu J, Li C and He J 2018 Tailoring charge transport in epoxy based composite under temperature gradient using $\mathrm{K}_{2} \mathrm{Ti}_{6} \mathrm{O}_{13}$ and asbestine whiskers Journal of Physics D-Applied Physics $\mathbf{5 1}$

[54] Ootera $\mathrm{H}$ and Nakanishi K 1988 Analytical method for evaluating surface charge distribution on a dielectric from capacitive probe measurement-application to a cone-type spacer in +or-500 kV DC-GIS IEEE Transactions on Power Delivery 3 165-72

[55] Nitta T and Nakanishi K 1991 Charge accumulation on insulating spacers for HVDC GIS IEEE Transactions on Electrical Insulation 26 $418-27$

[56] Fujinami H, Takuma T, Yashima M and Kawamoto T 1989 Mechanism and Effect of DC Charge Accumulation on $\mathrm{SF}_{6} \mathrm{Gas}_{\text {Insulated }}$ Spacers IEEE Power Engineering Review 962 -

[57] Cooke C M and Trump J G 1973 Post-Type Support Spacers for Compressed Gas-Insulated Cables IEEE Transactions on Power Apparatus and Systems PAS-92 1441-7

[58] Nakanishi K, Yoshioka A, Arahata Y and Shibuya Y 1983 Surface Charging On Epoxy Spacer At Dc Stress In Compressed SF 6 GAS IEEE Transactions on Power Apparatus and Systems PAS-102 3919-27

[59] Hasegawa T, Yamaji K, Hatano M, Endo F, Rokunohe T and Yamagiwa T 1997 Development of insulation structure and enhancement of insulation reliability of $500 \mathrm{kV}$ DC GIS IEEE Transactions on Power Delivery 12 194-202

[60] Volpov E 2004 Dielectric strength coordination and generalized spacer design rules for HVAC/DC $\mathrm{SF}_{6}$ gas insulated systems IEEE Transactions on Dielectrics and Electrical Insulation 11 949-63 
[61] Tu Y, Chen G, Li C, Wang C, Ma G, Zhou H, Ai X and Cheng Y 2019 100-kV HVDC SF 6 / $\mathrm{N}_{2}$ Gas-Insulated Transmission Line IEEE Transactions on Power Delivery 1-

[62] Jia Z, Zhang Q, Zhang B, Fan J, Li J and Li P 2009 Flashover characteristics of insulators in $\mathrm{SF}_{6}$ under DC High voltage technology 35 1903-7 (in Chinese)

[63] Liang H, Du B, Li J, Li Z and Li A 2018 Effects of non-linear conductivity on charge trapping and de-trapping behaviours in epoxy/SiC composites under DC stress IET Science, Measurement \& Technology 12 83-9

[64] Li J, Liang H, Du B and Wang Z 2019 Surface Functional Graded Spacer for Compact HVDC Gaseous Insulated System IEEE Transactions on Dielectrics and Electrical Insulation 26 664-7

[65] Du B, Liang H, Li J and Zhang C 2018 Temperature dependent surface potential decay and flashover characteristics of epoxy/SiC composites IEEE Transactions on Dielectrics and Electrical Insulation 25 631-8

[66] He S, Li C, Lin C, Hu J, He J and Sun Z 2019 Feasibility analysis and verification of potential application of nonlinear materials in charge control of gas-solid interface Journal of Power System and Automation 1-7 (in Chinese)

[67] Du B, Liang H and Li J 2019 Interfacial E-Field Self-Regulating Insulator Considered for DC GIL Application IEEE Transactions on Dielectrics and Electrical Insulation 26 801-9

[68] Xue J, Chen J, Dong J, Sun G, Deng J and Zhang G-J 2020 A novel sight for understanding surface charging phenomena on downsized HVDC GIL spacers with non-uniform conductivity International Journal of Electrical Power \& Energy Systems 120105979

[69] Xue J, Chen J, Dong J, Wang H, Li W, Deng J and Zhang G 2019 The regulation mechanism of SiC/epoxy coatings on surface charge behavior and flashover performance of epoxy/alumina spacers Journal of Physics D-Applied Physics $\mathbf{5 2} 405502$

[70] Xue J, Li Y, Dong J, Chen J, Li W, Deng J and Zhang G 2020 Surface charge transport behavior and flashover mechanism on alumina/epoxy spacers coated by SiC/epoxy composites with varied SiC particle size Journal of Physics D Applied Physics $\mathbf{5 3} 155503$

[71] Pan Z, Tang J, Pan C, Luo Y, Liu Q and He H 2020 Contribution of Nano-SiC/Epoxy Coating with Nonlinear Conduction Characteristic to Surface Charge Accumulation under DC Voltage Journal of Physics D: Applied Physics

[72] Li C, Lin C, Hu J, Liu W, Li Q, Zhang B, He S, Yang Y, Liu F and He J 2018 Novel HVDC Spacers by Adaptively Controlling Surface Charges - Part I: Charge Transport and Control Strategy IEEE Transactions on Dielectrics and Electrical Insulation 25 1238-47

[73] Li C, Lin C, Yang Y, Zhang B, Liu W, Li Q, Hu J, He S, Liu X and He J 2018 Novel HVDC spacers by adaptively controlling surface charges - part ii: experiment IEEE Transactions on Dielectrics and Electrical Insulation 25 1248-58

[74] Li C, Lin C, Zhang B, Liu W, Yang Y, Liu F, Liu X, Hu J and He J 2018 Novel HVDC spacers by adaptively controlling surface charges part iii: industrialization prospects IEEE Transactions on Dielectrics and Electrical Insulation 25 1259-66

[75] Li C, Liu B, Wang J, Gong R, Wang G, Lei Z, Fabiani D, Lin C and Hu J 2019 Novel HVDC Spacers in GIS/GIL by Adaptively Controlling Surface Charges - Insulation Compounding Scheme. In: 2019 2nd International Conference on High Voltage Engineering and Power Systems (ICHVEPS), pp 268-71

[76] Götz T, Kosse M, Riechert U, Abbasi A, Castellon J, Cavallini A, Esterl F, Geissler M, Hochbrückner B, Kharezy M, Küchler A, Markalous S, Neuhold S, Pietsch R, Pirker A, Plath R, Reuter M, Rossner M and Seltzer-Grant M 2019 Progress on Partial discharge detection under DC voltage stress Interim Report of WG D1.63

[77] Zhang G, Wang X, Yan Z, Liu Y, Okada M, Yasuoka K and Ishii S 2002 Optical studies of surface discharge under de voltage in vacuum IEEE Transactions on Dielectrics and Electrical Insulation 9 187-93 doi: 10.1109/94.993734.

[78] Griseri V, Dissado L A, Fothergill J, Teyssedre G and Laurent C 2002 Electroluminescence excitation mechanisms in an epoxy resin under divergent and uniform field IEEE Transactions on Dielectrics and Electrical Insulation 9 150-60

[79] Lin C et al Luminescence reveals micro discharge triggered surface flashover submitted to JPD

[80] Shao T, Wang R, Zhang C, Yan P 2018 Atmospheric-pressure pulsed discharges and plasmas: mechanism, characteristics and applications High Voltage 3 14-20.

[81] Shao T, Yang W, Zhang C, Niu Z, Yan P and Schamiloglu E 2014 Enhanced surface flashover strength in vacuum of polymethylmethacrylate by surface modification using atmospheric-pressure dielectric barrier discharge Applied Physics Letters 105

[82] Du B, Liang H and Li J 2019 Surface Coating Affecting Charge Distribution and Flashover Voltage of Cone-type Insulator under DC Stress IEEE Transactions on Dielectrics and Electrical Insulation 26 714-21 
[83] Zhang B, Wang Q, Zhang Y, Gao W, Hou Y and Zhang G 2019 A self-assembled, nacre-mimetic, nano-laminar structure as a superior charge dissipation coating on insulators for HVDC gas-insulated systems Nanoscale 11 18046-51

[84] Iwabuchi H, Donen T, Matsuoka S, Kumada A, Hidaka K, Hoshina Y and Takei M 2012 Influence of Surface-Conductivity Nonuniformity on Charge Accumulation of GIS Downsized Model Spacer under DC Field Application Electrical Engineering In Japan 181 29-36

[85] Xue J, Wang H, Chen J, Li K, Liu Y, Song B, Deng J and Zhang G 2018 Effects of surface roughness on surface charge accumulation characteristics and surface flashover performance of alumina-filled epoxy resin spacers Journal of Applied Physics 124

[86] Chu P, Zhang H, Zhao J, Gao F, Guo Y, Dang B and Zhang Z 2017 On the volume resistivity of silica nanoparticle filled epoxy with different surface modifications Composites Part a-Applied Science And Manufacturing 99 139-48

[87] Hanna R, Lesaint O, and Zavattoni L 2016 Dark Current Measurements in Humid SF 6 at High Uniform Electric Field. In: IEEE Conference on Electrical Insulation and Dielectric Phenomena, pp 19-22

[88] Zavattoni L, Hanna R, Lesaint $\mathrm{O}$ and Gallot-Lavallee O 2015 Dark current measurements in humid $\mathrm{SF}_{6}$ : influence of electrode roughness, relative humidity and pressure Journal of Physics D-Applied Physics 48

[89] Zavattoni L, Lesaint O and Gallot-Lavallee O 2013 Dark Current Measurements in Pressurized Air, N2, and SF 6 . In: IEEE Conference on Electrical Insulation and Dielectric Phenomena, pp 659-62

[90] Messerer F and Boeck W 1999 High resistance surface coating of solid insulating components for HVDC metal enclosed equipment. In: 1999 Eleventh International Symposium on High Voltage Engineering, pp 63-6 vol.4

[91] Messerer F, Finkel M and Boeck W 2002 Surface charge accumulation on HVDC-GIS-spacer. In: Conference Record of the the 2002 IEEE International Symposium on Electrical Insulation (Cat. No.02CH37316), pp 421-5

[92] Winter A, Kindersberger J, Tenzer M, Hinrichsen V, Zavattoni L, Lesaint O, Muhr M and Imamovic D 2015 Solid/Gaseous Insulation Systems for Compact HVDC Solutions Cigre Science \& Engineering 1

[93] Winter A, Kindersberger J, Hinrichsen V, Imamovic D and Tenzer M 2013 Compact Gas-Solid Insulating Systems for High-Field-Stress in HVDC applications In: CIGRE Study Committee B3 \& Study Committee D1 Colloquium

[94] Zhang B and Zhang G 2018 A Summary of the Research on the Charge Characteristics of the Solid-Gas Interface in DC GIL II : Charge Regulation and Suppression Strategies Journal of Electrical Engineering 33 5145-58 (in Chinese)

[95] Mangelsdorf C W and Cooke C M 1978 Static charge accumulated by epoxy post insulation stressed at high DC voltages. In: Conference on Electrical Insulation \& Dielectric Phenomena - Annual Report 1978, pp 220-7

[96] CIGRÉ Working Group D1.03 (TF11) E, F., Giboulet A, Girodet A, Hama H, Hanai M, Juhre K, Kindersberger J, Koltunowicz W, Kranz H-G, Meijer S, Neumann C, S. O, Riechert U and Schichler U 2012 Gas Insulated Systems for HVDC: DC Stress at DC and AC Systems CIGRÉ Brochure

[97] Riechert U, Hama H, Endo F, Juhre K, Kindersberger J, Meijer S, Neumann C, Okabe S and Schichler U On behalf of CIGRÉ Task Force D1.03.11. 2010 Gas Insulated Systems for HVDC. In: 2010 ETG Fachtagung: Isoliersysteme bei Gleich- und Mischfeldbeanspruchung,( Köln, Germany

[98] Straumann U, Schueller M and Franck C 2012 Theoretical Investigation of HVDC Disc Spacer Charging in SF 6 Gas Insulated Systems IEEE Transactions on Dielectrics and Electrical Insulation 19 2196-205

[99] Gremaud R, Molitor F, Doiron C, Krivda A, Christen T, Johansson K, Lavesson N, Riechert U and Straumann U 2013 Solid-gas interfaces in DC gas insulated systems. In: 4. ETG-Fachtagung Grenzflächen in elektrischen Isoliersystemen: Beanspruchungen, Design, Prüfverfahren, Lebensdauer 12.-13., (Dresden, Germany

[100] Gremaud R, Doiron C, Baur M, Simka P, Teppati V, Kallstrand B, Johansson K, Kosse M, Speck J, Großmann S, Riechert U and Straumann U 2016 Solid-gas insulation in HVDC gas-insulated system: Measurement, modeling and experimental validation for reliable operation. In: CIGRÉ Report D1-101, 46th CIGRÉ Session, (Palais des Congrès de Paris, Paris, France

[101] Riechert U, Straumann U and Gremaud R 2016 Compact gas-insulated systems for high voltage direct current transmission: Basic design. In: 2016 IEEE PES Transmission \& Distribution Conference \& Exposition (T\&D), (Kay Bailey Hutchison Convention Center Dallas, Texas, USA pp 1-5

[102] Riechert U, Straumann U, Gremaud R and Callavik M 2016 Compact gas-insulated systems for high voltage direct current transmission: Design and testing. In: 2016 IEEE PES Transmission \& Distribution Conference \& Exposition (T\&D), (Kay Bailey Hutchison Convention Center Dallas, Texas, USA pp 1-5 
[103] Salthouse E C and McIlhagger D S 1962 The measurement of surface resistivity. In: Proceedings of the IEE - Part A: Power Engineering, pp $41-4$

[104] Zhao W, Zhang G and Yan Z 2007 Influence of Trap Parameters of Composite Materials on Its Flashover Characteristics Under High Voltage Pulses in Vacuum Chinese Society for Electrical Engineering 11-7 (in Chinese)

[105] Winter A and Kindersberger J 2012 Stationary Resistive Field Distribution along Epoxy Resin Insulators in Air under DC Voltage IEEE Transactions on Dielectrics and Electrical Insulation, 19 1732-9

[106] Kindersberger J and Lederle C 2008 Surface charge decay on insulators in air and sulfurhexafluorid - Part I: Simulation IEEE Transactions on Dielectrics and Electrical Insulation,15 941-8

[107] Kindersberger J and Lederle C 2008 Surface charge decay on insulators in air and sulfurhexafluorid - Part II: Measurements IEEE Transactions on Dielectrics and Electrical Insulation, 15 949-57 